Lappeenranta University of Technology

School of Engineering Science

Erasmus Mundus Masters in Pervasive Computing and Communications

for Sustainable Development (PERCCOM)

Marcel Lowell G. Villanueva

USING GESTURES TO INTERACT WITH

HOME AUTOMATION SYSTEMS

Examiners: Prof. Eric Rondeau (University of Lorraine)

Prof. Jari Porras (Lappeenranta University of Technology)

Prof. Karl Andersson (Luleå University of Technology)

Supervisors: Prof. Dr. Olaf Droegehorn

Hochschule Harz - University of Applied Sciences

Wernigerode, Germany 
This thesis is prepared as part of a European Erasmus Mundus programme PERCCOM Pervasive Computing and Communications for Sustainable Development [1].
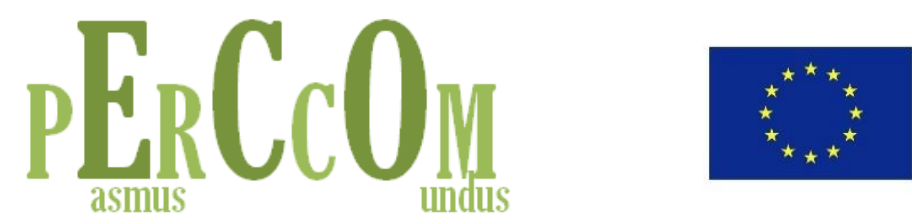

Co-funded by the Erasmus+ Programme of the European Union

This thesis has been accepted by partner institutions of the consortium (cf. UDL-DAJ, $\mathrm{n}^{\circ} 1524,2012$ PERCCOM agreement).

Successful defense of this thesis is obligatory for graduation with the following national diplomas:

- Master in Complex Systems Engineering (University of Lorraine)

- Master of Science in Technology (Lappeenranta University of Technology)

- Master of Science in Computer Science and Engineering, specialization in Pervasive Computing and Communications for Sustainable Development (Luleå University of Technology) 


\begin{abstract}
Lappeenranta University of Technology

School of Engineering Science

Erasmus Mundus Masters in Pervasive Computing and Communications

for Sustainable Development (PERCCOM)
\end{abstract}

Marcel Lowell G. Villanueva

\title{
Using gestures to interact with home automation systems
}

Master's Thesis

70 pages, 26 figures, 18 tables, 4 appendices

Keywords: home automation, gesture control, usability, pervasive computing

Homes and working spaces are considered significant contributors of energy consumption and carbon emissions worldwide. Previous studies in the field of home- and building automation have demonstrated the sustainability gain brought by smart home solutions, in terms of energy-efficiency, economic savings, and enhanced living and working conditions. A major barrier, however, to the adoption of these solutions is the complexity and limited usability of user interfaces. As a response to these challenges, this study investigates the use of gestures as a natural way of controlling and interacting with home automation systems. Using the available motion capture technology, a gesture dictionary will be defined as a set of meaning actions in free-form and in-air movements. A usability test will be conducted to measure the resulting socio-technical aspects. Lastly, the study will present the analysis and effects of gestures control for a higher up-take of smart home solutions towards designing and maintaining buildings of the future that are both user-centric and resource efficient to reduce our overall carbon footprint. 


\section{ACKNOWLEDGEMENTS}

The author extends his sincerest gratitude to the following people who made this graduate thesis possible and a worthwhile endeavor.

To Prof. Olaf Droegehorn, my thesis supervisor, for the utmost patience and sincerity for keeping up with my quirks. After all the long consultation hours spent during the formulation, implementation and documentation of the thesis, and personal mentoring that made this study possible, thank you very much.

To Prof. Jean-Philippe Georges, Prof. Jari Porras, and Prof. Karl Andersson, the country coordinators, for the knowledge shared during the early stages of the thesis, and the appraisals given with our accomplishments during final presentation of this thesis.

To Prof. Eric Rondeau, the PERCCOM programme coordinator, who inspired me to pursue this undertaking with hopes of realizing the real-world applications of technology and innovation to help address issues on sustainability. Thank you for choosing to grant me this Erasmus Mundus Master scholarship, and for the trust as I fulfill my duties as the former Erasmus Mundus Association programme representative for PERCCOM.

To the PERCCOM Consortium, the faculty of professors from our different universities, and the industrial partners who guided me in shaping the knowledge that helped me accomplish the tasks needed in this research.

To all the university and administrative staffs from France, Finland, Russia, United Kingdoms, Sweden, and Germany, especially to Caroline Schrepff, our very hardworking PERCCOM secretary, for the time they dedicated in answering my questions, preparing necessary documents for us, and for making sure of our smooth mobility from different countries.

To the European Commission responsible for the Erasmus+ programmes, for this one-of-a-kind learning experience of sharing myself with the world. Thank you! 
To PERCCOM Cohort 4, my good friends, my family away from home, my dear colleagues, for the morale boost and whose help I would always be grateful for. Now it's time for us to leave our mark!

To my sisters and titas, for always making sure that I am taking care of myself.

To my beloved parents, for giving me all of life's comfort, and the opportunity to have quality education, which lead me to where I am today. I love you.

To my grandparents.

To the Philippines, and the Filipino people.

And to our Almighty God to whom we bring up everything for His greater glory!

Marcel Lowell G. Villanueva

Wernigerode (Harz), Germany

July 4, 2018 


\section{TABLE OF CONTENTS}

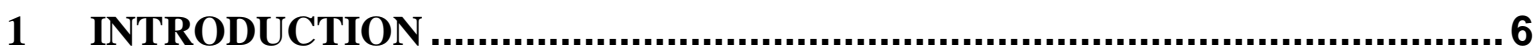

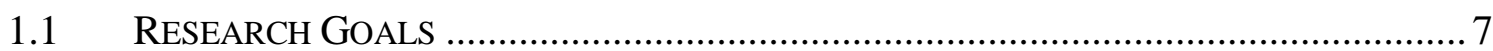

1.2 RESEARCH QUESTIONS AND OBJECTIVES.....................................................

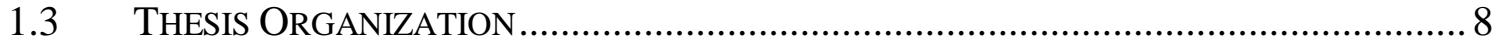

2 METHODOLOGY

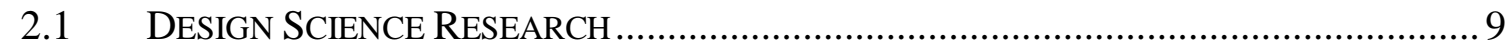

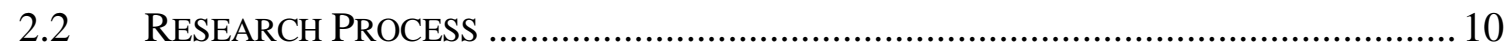

$3 \quad$ REVIEW OF RELATED WORKS …….................................................. 12

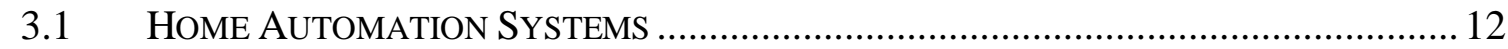

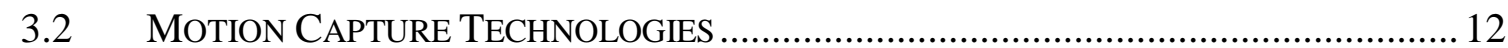

3.3 GESTURE INTERACTION \& SOCIO-TECHNICAL ASPECTS .......................................... 18

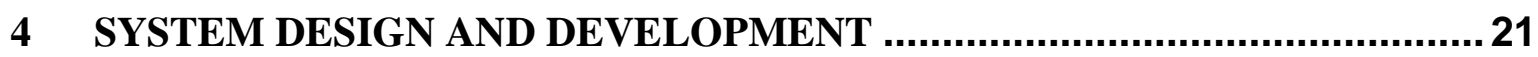

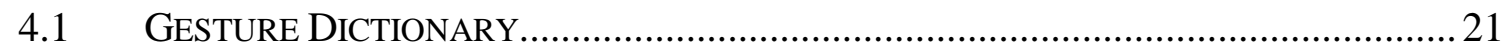

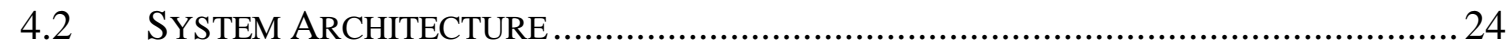

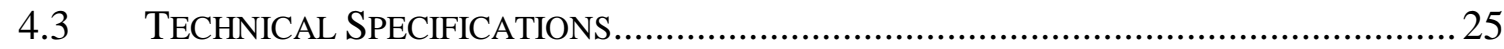

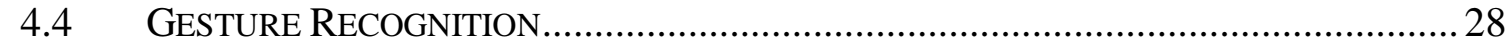

4.5 LIKERT ITEMS FOR TESTING........................................................................... 30

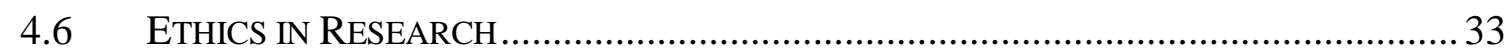

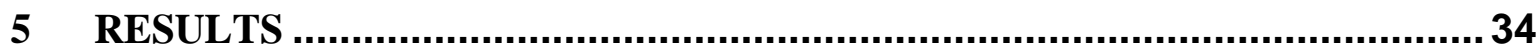

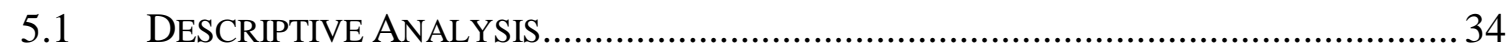

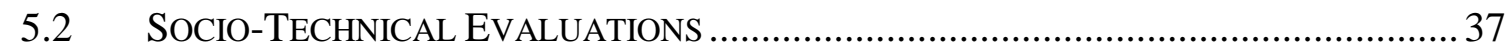

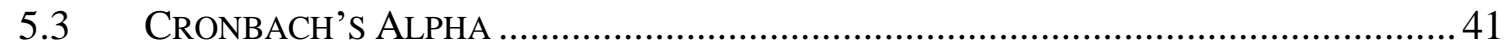

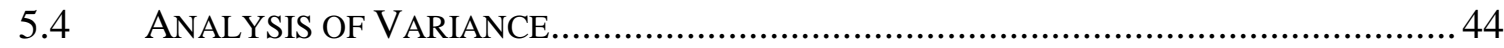

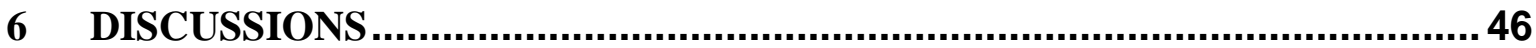

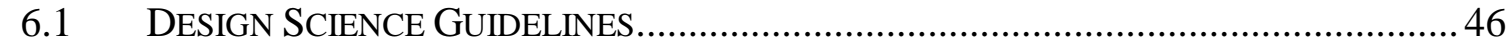

6.2 GaP ANALYSIS AND NOVEL CONTRIBUTION..................................................... 48

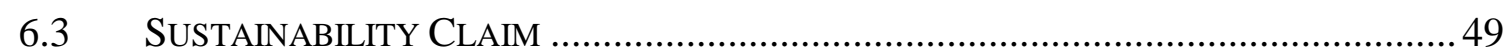




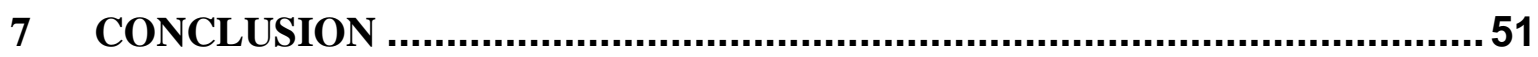

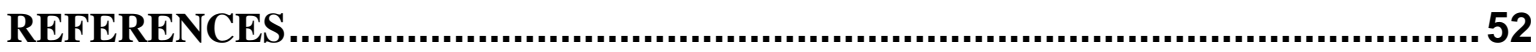

APPENDICES 


\section{LIST OF FIGURES}

Fig. 1 Design Science Research..................................................................................

Fig. 2 Five-stage Research Workflow ……………………………………………......11

Fig. 3 Classification of Gesture-based Human Computer Interactions .................................13

Fig. 4 Photos of Kinect sensor application at home, (a) in the kitchen, (b) the ambient

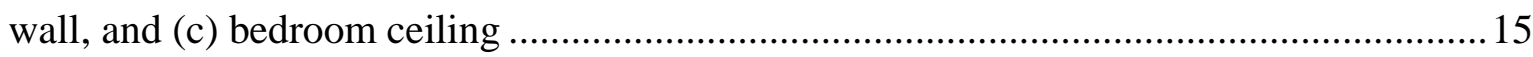

Fig. 5 The Leap Motion Controller.................................................................................. 16

Fig. 6 Framework of Socio-technical Aspects for Gesture Interaction ................................19

Fig. 7 Gesture dictionary visualized with Microsoft Kinect (Summary) .............................21

Fig. 8 System architecture diagram for HAS gesture interaction ........................................24

Fig. 9 Microsoft Kinect Parts and Specifications ................................................................25

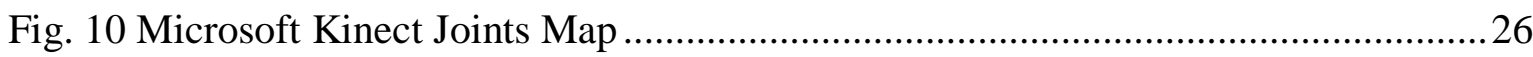

Fig. 11 LEAP Motion Control Parts and Specifications....................................................26

Fig. 12 LEAP Motion Control Joints Map ....................................................................22

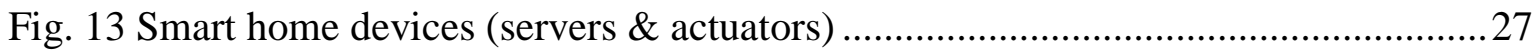

Fig. 14 The machine learning approach.........................................................................28

Fig. 15 Using the Visual Gesture Wizard to initiate gesture recognition ..............................29

Fig. 16 Labelling gestures using Visual Gesture Builder ...................................................29

Fig. 17 Setting up masks for post-processing (a) AdaBoost, and (b) RFR Progress............30

Fig. 18 Photos taken during the demo and testing .......................................................... 31

Fig. 19 Graph for the level of technological aptitude (Liker scale: 1-5) .............................34

Fig. 20 Graph showing distribution of participants who own smart home devices..............35

Fig. 21 Graph of smart home devices some participants own ..............................................35

Fig. 22 Graph showing the distribution of participants who does not own any smart home devices but are interested to have them at home...............................................................36

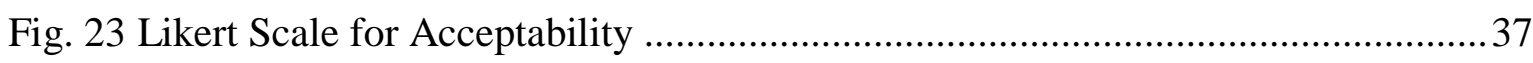

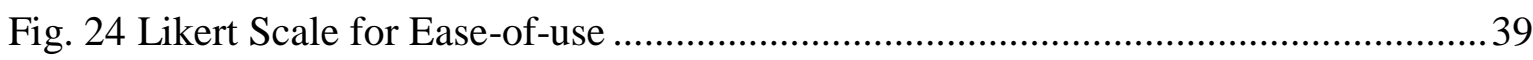

Fig. 25 Likert Scale for Culturability ......................................................................... 40 


\section{LIST OF TABLES}

Table 1 Objectives \& Action Plan ..................................................................................

Table 2 Design Science Research Guidelines [8] ............................................................. 10

Table 3 Design Science Research Guidelines.................................................................11

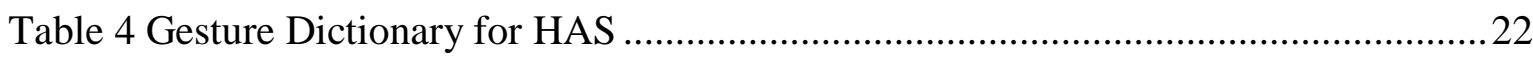

Table 5 Likert items for Acceptability ………………………………………………..... 31

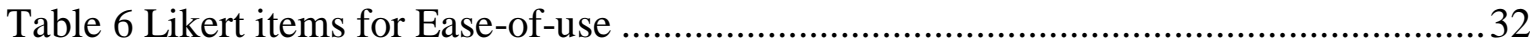

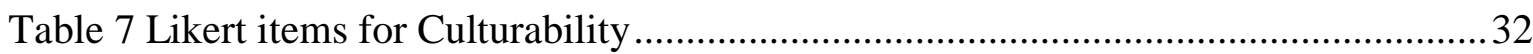

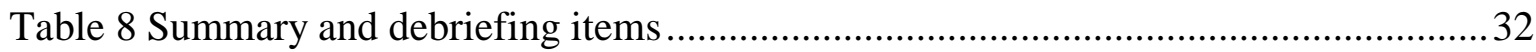

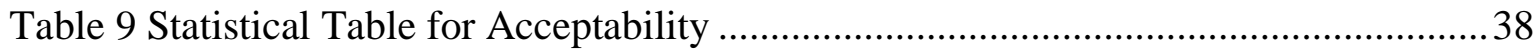

Table 10 Statistical Table for Ease-of-use ..........................................................................39

Table 11 Statistical Table for Culturability ....................................................................40

Table 12 Statistical Table for Summary/ Debriefing Questions ...........................................41

Table 13 Statistical Table of Participants (Cronbach's Alpha) ……….................................42

Table 14 Statistical Table for Questions (Cronbach's Alpha) …………………………......43

Table 15 Statistical Table Summry for Cronbach's Alpha ...................................................43

Table 16 Statistical Table Summary for ANOVA ………………………………………....4

Table 17 ANOVA: Single Factor Values ........................................................................4

Table 18 Sustainability Analysis Pentagon …………………………………………....49 


\section{LIST OF SYMBOLS AND ABBREVIATIONS}

$3 \mathrm{D}$

ANOVA

AR

ASL

BA

$\mathrm{CCW}$

$\mathrm{CW}$

DOE

EU

F

GDPR

GESI

HAS

$\mathrm{HCI}$

ICT

IR

ISO

LED

ML

MS

NUI

PEOU

PU

RGB

SDK

SS

TAM

USB

VR

XREF
Three-dimensional

Analysis of Variance

Augmented Reality

American Sign Language

Building Automation

Counter-clockwise

Clockwise

Degree(s) of Freedom

European Union

Fisher Value (as in F-Distribution)

General Data Protection Regulation

Global e-Sustainability Initiative

Home Automation Systems

Human-Computer Interaction

Information and Communication Technology

Infrared

International Standards Organization

Light Emitting Diode

Machine Learning

Mean-Squares

Natural User Interfaces

Perceived Ease-of-use

Perceived Usefulness

Red Green Blue

Software Development Kit

Sum of Squares

Technology Acceptance Model

Universal Serial Bus

Virtual Reality

External Reference File 


\section{INTRODUCTION}

In an article published by Eurostat regarding energy trends from data collected June of 2017, households comprise $25.4 \%$ of the final energy consumption, one of the dominant categories together with transport (33.1\%), and industry (25.3\%) within the European Economic region [2]. In addition, buildings, both homes and working spaces, are culpable for the $36 \%$ of the total carbon emissions in Europe [3]. The European Commission is convinced that by using commercially available building automation technologies, possible reductions to energy consumption can be up to $6 \%$, and $5 \%$ for the total carbon emissions [3]. Through its policies, initiatives, and research activities, the European Union pushes its citizens to use energy more efficiently - to lower their utility bills, reduce their reliance on external suppliers of oil and gas, and help protect the environment.

The Global e-Sustainability Initiative (GeSI) suggests in its \#Smarter2030 Report that ICT in households and buildings will increase comfort and reduce energy and water bills. The report adds that smart building solutions could cut up to 2.0Gt of carbon emissions from the housing sector, reducing energy consumption by 5 billion $\mathrm{MWh}$, and creating revenue opportunities of another $\$ 260$ billion [4]. The future of smart buildings relies on the concept of insight and control, from smart metering that enhances people's awareness of their energy and resource consumption to enabling users to interact with these technologies remotely and automatically. These solutions will lead to strong sustainability impacts such as energy and resource efficiency, improved processes and automation, and enhance living conditions and productivity.

Home automation technologies have been commercially available for a couple of years now, these solutions repeatedly faced market failures. Amid all the benefits, low usability can be seen as one of the prominent reasons for the high level of reluctance from customers to invest in home automation systems (HAS) [5]. Other factors include high investment cost, lack of flexibility and scalability, and the variety of individual products that are not easily interoperable. However, the user interface and control are often reported to be the most unusable product due to its poor design and complex features which result in home automation technologies being inaccessible to a wide range of non-technical users [5]. 


\subsection{Research Goals}

This study aims to investigate on the use of gesture control as a natural way of interacting with home automation systems. In addition, there will a look into socio-technical aspects such as acceptability, ease-of-use, and culturability. The following research questions will serve as milestones to gauge a level of comprehensiveness toward a successful implementation of this study.

\subsection{Research Questions and Objectives}

This study has the following Research Questions (RQ):

RQ1: What are the available motion capture technologies in the context of this research that can be used to interact with home automation systems?

RQ2: What are possible gestures to be defined as meaningful actions to control smart home devices?

RQ3: How do we evaluate the impact of gestures and perceptual technologies considering both human and technical factors towards adopting home automation systems?

Each research question mentioned above will be translated into research objectives structural action plans that would be reflected in the methodology. These objectives are as follows:

(a) Technology Survey: Explore available motion capture technologies in the context of home automation systems.

(b) Gesture Definition: Define gestures as meaningful actions to control smart home devices.

(c) Socio-technical Study: Conduct a socio-technical study for the system to measure the level of acceptability, ease-of-use, and culturability. 
Table 1 Objectives \& Action Plan

\begin{tabular}{|l|l|l|}
\hline \multicolumn{1}{|c|}{ TECHNOLOGY SURVEY } & \multicolumn{1}{|c|}{ GESTURE DEFINITION } & SOCIO-TECHNICAL STUDY \\
\hline $\begin{array}{l}\text { Research on available hand } \\
\text { gesture technology. }\end{array}$ & $\begin{array}{l}\text { Research on previous studies } \\
\text { with gesture definitions for } \\
\text { home automation. }\end{array}$ & $\begin{array}{l}\text { Study statistical methods for } \\
\text { doing a usability test. }\end{array}$ \\
\hline $\begin{array}{l}\text { Acquire and play around with } \\
\text { at least two (2) sensors. }\end{array}$ & $\begin{array}{l}\text { Formulate a data collection } \\
\text { approach to give meanings } \\
\text { out of hand gestures. }\end{array}$ & $\begin{array}{l}\text { Formulate survey questions } \\
\text { and identify the study's } \\
\text { populations. }\end{array}$ \\
\hline $\begin{array}{l}\text { Bridge and integrate sensors } \\
\text { with smart home devices (e.g. } \\
\text { FHEM, etc.) }\end{array}$ & $\begin{array}{l}\text { Define a gesture dictionary for } \\
\text { this specific application. }\end{array}$ & $\begin{array}{l}\text { Disseminate survey and demo } \\
\text { prototype (if necessary) to } \\
\text { collect data to be analyzed. }\end{array}$ \\
\hline
\end{tabular}

\subsection{Thesis Organization}

This manuscript is organized as follows: Chapter 1 introduced the main topic - an overview, the research goals, motivations, and objectives. Chapter 2 presents the research framework and the process workflow that the study will be based on. In Chapter 3, related works on the topics of home automation systems, motion capture technologies, and gesture interactions will be discussed. The implementation will be outlined and elaborated in Chapter 4 . This would include the technical specifications, and the gesture definition. Chapter 5 will be about the study of the socio-cultural aspects with demo and testing. In Chapter 6, the analysis of results, research findings and discussions, and sustainability claim will be address. Finally, the study will be wrapped up in Chapter 7 as the conclusion and recommendations for future studies. 


\section{METHODOLOGY}

In this chapter, both the high-level (Design Science Research) and the low-level research process will be tackled, dealt with, and explained. Each section will give a detailed profile the methodology used as the framework and skeleton of the research. It is rather important to point the significance and relevance of logic behind the methodology, and these will be presented in the following sections.

\subsection{Design Science Research}

Design science research can be seen as an embodiment of three closely related cycles of activities. The relevance cycle initiates design science research with an application context that not only provides the requirements for the research as inputs but also defines acceptance criteria for the ultimate evaluation of the research results. The rigor cycle provides past knowledge to the research project to ensure its innovation. It is contingent on the researchers to thoroughly research and reference the knowledge base in order to guarantee that the designs produced are research contributions and not routine designs based upon the application of well-known processes. The central design cycle iterates between the core activities of building and evaluating the design artifacts and processes of the research - for the purpose of this thesis, action research methodology will take over the design cycle towards implementing the artifact [6].

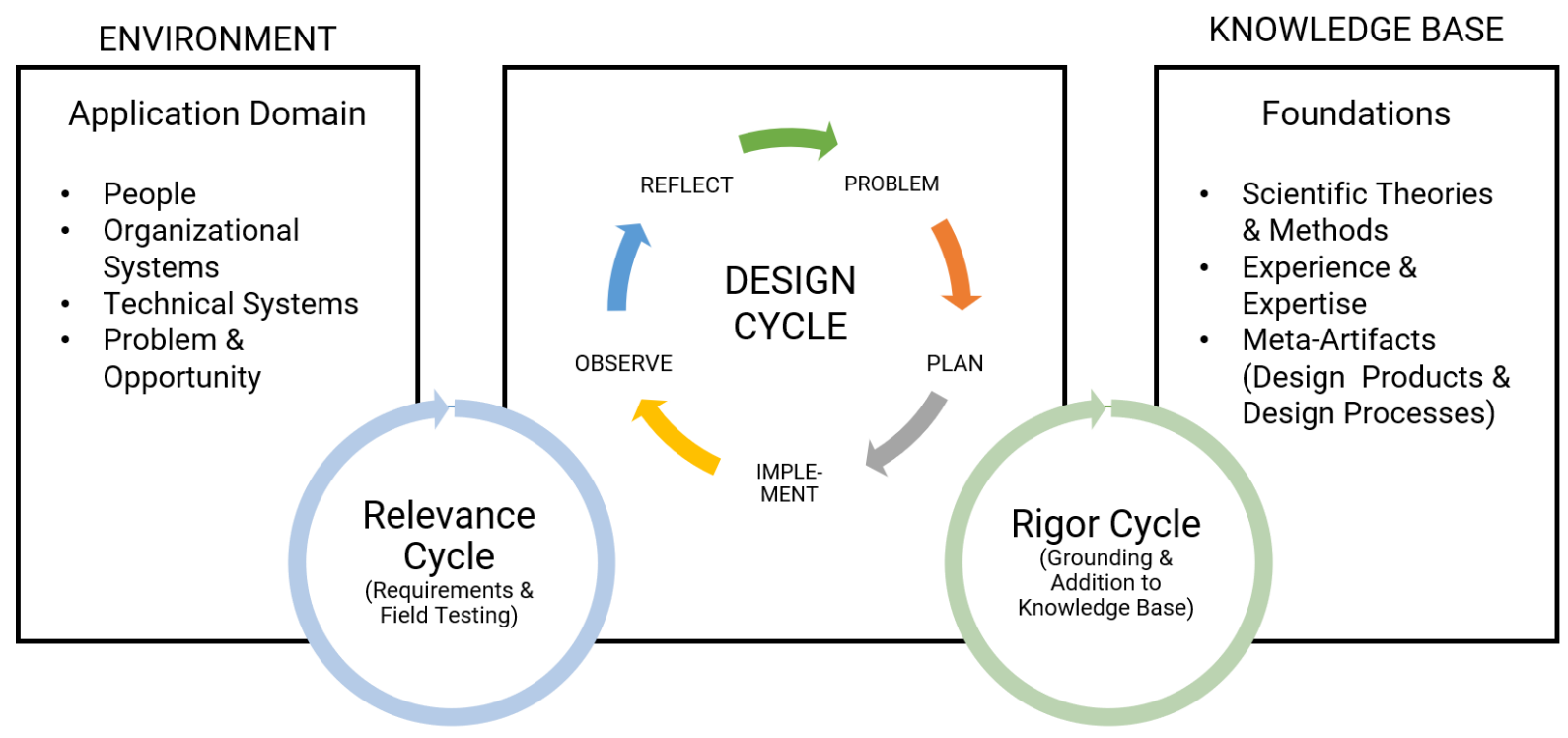

Fig. 1 Design Science Research 
This was adopted from the design science research process suggested by Tran (2017) [7]. A five-stage design cycle process was based on the Design Science Framework [6] and served as the micro-level methodology for this study.

Table 2 Design Science Research Guidelines [8]

\begin{tabular}{ll}
\hline \multicolumn{1}{c}{ GUIDELINES } & \multicolumn{1}{c}{ DESCRIPTION } \\
\hline 1. Design as an Artifact & $\begin{array}{l}\text { Design science research must produce a viable artifact in the } \\
\text { form of a construct, a model, a method, or an instantiation. }\end{array}$ \\
\hline 2. Problem Relevance & $\begin{array}{l}\text { The objective of design science research is to develop } \\
\text { technology-based solutions to important and relevant problems. }\end{array}$ \\
\hline 3. Design Evaluation & $\begin{array}{l}\text { The utility, quality, and efficacy of a design artifact must be } \\
\text { rigorously demonstrated via well-executed evaluation methods. }\end{array}$ \\
\hline 4. Research Contribution & $\begin{array}{l}\text { Effective design science research must provide clear and } \\
\text { verifiable contributions in the areas of design artifact, design } \\
\text { foundations, and/or design methodologies. }\end{array}$ \\
\hline 5. Research Rigor & $\begin{array}{l}\text { Design Science research relies upon the application of rigorous } \\
\text { methods in both the construction and evaluation of the design } \\
\text { artifact. }\end{array}$ \\
\hline $\begin{array}{l}\text { 6. Design as a Search } \\
\text { Process }\end{array}$ & $\begin{array}{l}\text { The search of an effective artifact requires utilizing available } \\
\text { means to reach desired ends while satisfying laws in the } \\
\text { problem environment. }\end{array}$ \\
\hline 7. Communication of & $\begin{array}{l}\text { Design science research must be presented effectively both to } \\
\text { technology-oriented as well as research-oriented audiences. }\end{array}$ \\
\hline
\end{tabular}

These design science research guidelines will be reiterated in the discussion chapter to crosscheck whether the study held true to these guidelines.

\subsection{Research Process}

The workflow will have five stages where components of the design science research are incorporated. First, problem identification which include literature review, corresponds to knowledge-base and grounding from the Rigor Cycle. Requirement Definition (from Relevance Cycle) will include technology survey and gesture definition while Artifact Development (Design Cycle) encompassed proof-of-concept and prototyping. To complete the Design Cycle, we move to Observation \& Feedback with the usability testing; and Evaluation with the analysis and discussion towards a coherent conclusion of the research. 


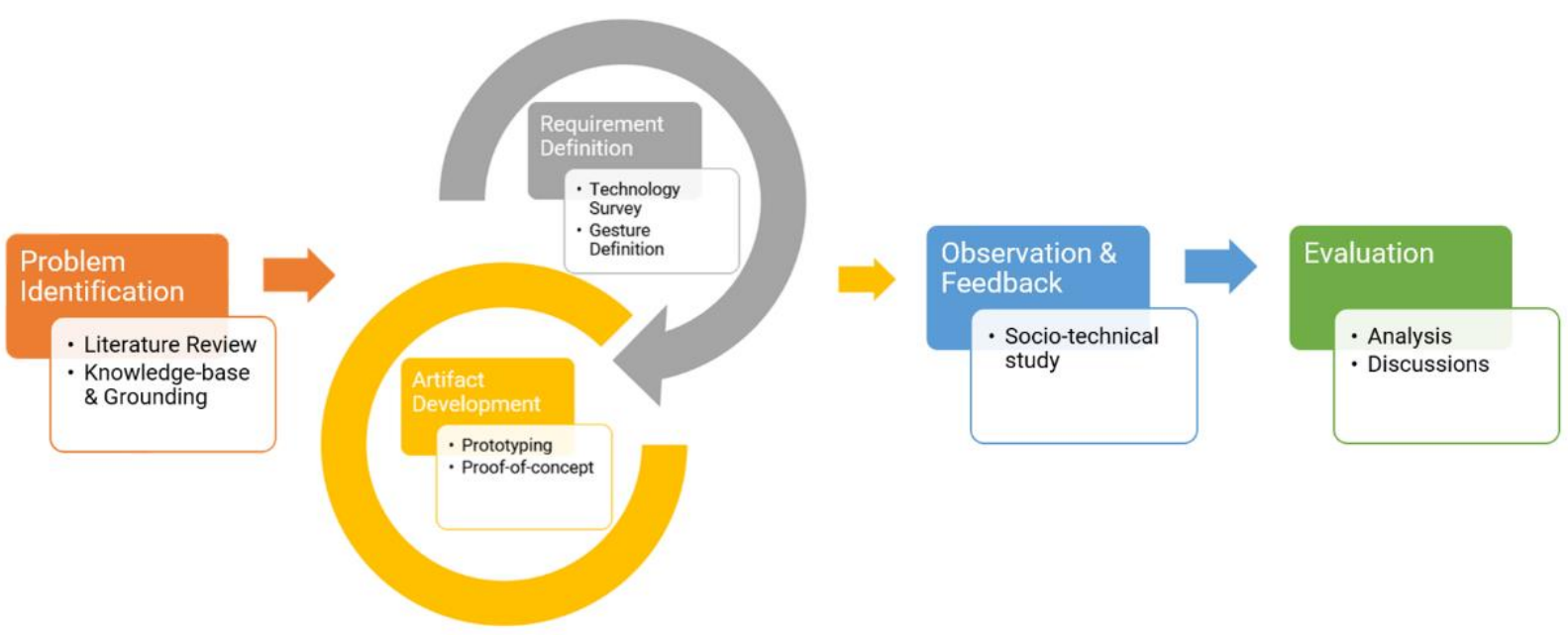

Fig. 2 Five-stage Research Workflow

Table 3 Design Science Research Guidelines

\begin{tabular}{|c|c|c|c|}
\hline WORKFLOW STAGE & $\mathbf{R Q}$ & DSR CYCLE & DESCRIPTION \\
\hline $\begin{array}{l}\text { 1. Problem } \\
\text { Identification }\end{array}$ & $\mathrm{RQ} 1$ & Rigor Cycle & $\begin{array}{l}\text { This includes literature review } \\
\text { and survey of related works to } \\
\text { build up the knowledge-base } \\
\text { and grounding. }\end{array}$ \\
\hline $\begin{array}{l}\text { 2. Requirement } \\
\text { Definition }\end{array}$ & $\mathrm{RQ}$ 1, RQ 2 & Relevance Cycle & $\begin{array}{l}\text { This comprises the survey of } \\
\text { available technologies and } \\
\text { definition of actions for the } \\
\text { gesture dictionary. This loops } \\
\text { with Stage 3: Artifact } \\
\text { Development. }\end{array}$ \\
\hline $\begin{array}{l}\text { 3. Artifact } \\
\text { Development }\end{array}$ & $\mathrm{RQ} 2$ & Design Cycle & $\begin{array}{l}\text { This includes prototyping and } \\
\text { the development of a proof-of- } \\
\text { concept. This loops with Stage } \\
\text { 2: Requirement Definition. }\end{array}$ \\
\hline $\begin{array}{l}\text { 4. Observation \& } \\
\text { Feedback }\end{array}$ & $\mathrm{RQ} 2, \mathrm{RQ} 3$ & Design Cycle & $\begin{array}{l}\text { This involves the socio- } \\
\text { technical study which further } \\
\text { includes the prototype } \\
\text { demonstration and the survey } \\
\text { questionnaires. }\end{array}$ \\
\hline 5. Evaluation & RQ 3 & Design Cycle & $\begin{array}{l}\text { This comprises the data } \\
\text { analysis of the Likert items and } \\
\text { drawing conclusions to initiate } \\
\text { discussions about the study. }\end{array}$ \\
\hline
\end{tabular}




\section{REVIEW OF RELATED WORKS}

This chapter will be divided into three sections dealing with the following topics: (a) home automation systems, (b) motion capture technologies, and (c) gesture interaction and usability. Each section will discuss previous studies, applications, and works that are either directly or indirectly but substantially related to this work.

\subsection{Home Automation Systems}

Previous studies in Home Automation and Smart Homes have various definitions of these common buzz words. David, et. al (2002) defines it as "the integration of technologies and services, applied to homes, flats, apartments, houses and small buildings with the purpose of automating them and obtaining and increasing safety and security, comfort, communication, and technical management" [9]. In another study Malcolm (2014) put it as "one where smart technologies are installed and where those technologies facilitate automatic or user-initiated communication, involving a range of appliances, sensors, actuators and switches" [10]. Martinez (2017) also referred to it as a derivative of Building Automation (BA) which is specifically implemented in homes and residential spaces [11]. These are the working definitions that will be used in the context of this research.

In the following chapters, the term Home Automation Systems (HAS) will be used to define the collective idea and concepts of home automation, smart homes, and domotics, which were loosely referred to in the literature and other related works. In addition, Smart Home Technologies will be the working term for all technologies, such as sensors, actuators, and similar devices that are used and integrated towards developing and implementing HAS.

\subsection{Motion Capture Technologies}

The release of the LEAP Motion Controller in 2013 opened new frontiers for gesture technologies. While the industry and tech enthusiasts differ in opinion on how useful the highly publicized device was, the sale of the product - along with the new generation. 


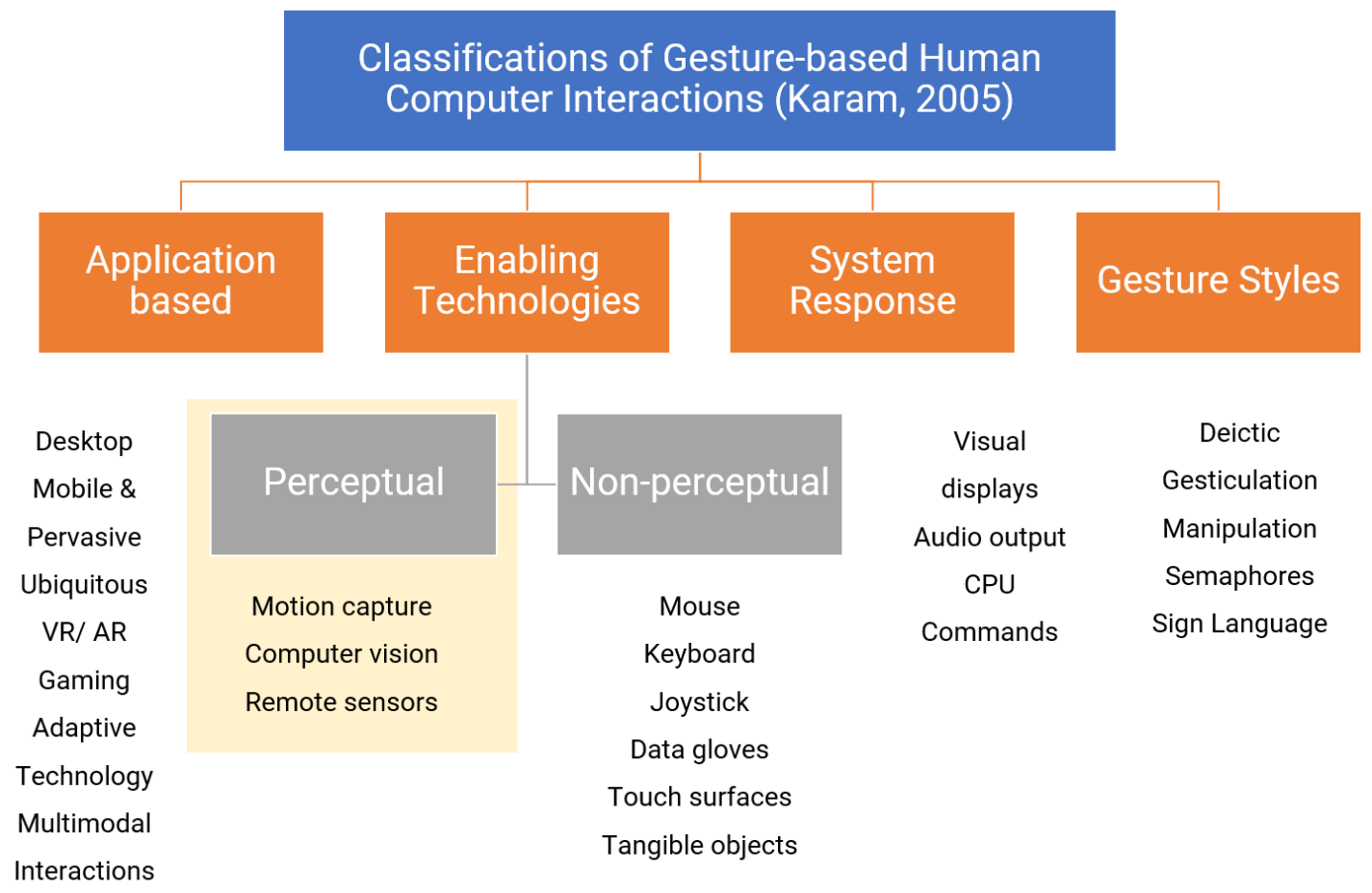

Fig. 3 Classification of Gesture-based Human Computer Interactions (Enabling Technologies: Perceptual and Non-perceptual)

XBOX Kinect sensor by Microsoft, marked a step forward for commercial gestural interface use [12]. We are interested with gestural interfaces for several reasons. Advances in technology have made gesture recognition more feasible and affordable in terms of low-cost and efficient microcontrollers, enhanced machine vision software, and state of the art 3D cameras and depth sensors [12].

Gesture control technologies or gestural interfaces can be categories to either perceptual or non-perceptual technologies [9][10]. Like how Karam \& Schraefel put it and as shown in Fig. 3, perceptual technologies are those which enables gestures to be recognized without requiring any physical contact with an input device or with any physical objects, allowing the user to communicate gesture without having to wear, hold or make physical contact with any intermediate devices [13]. Non-perceptual technologies, on the other hand, are those that involves the use of artifacts such as a glove, pen, or mouse, and requires physical contact to transmit spatial or temporal information as input.

For the purpose of this study, we focus on perceptual technologies, such as the Microsoft Kinect, in terms of its ability to enable gesture recognition without the need for physical 
contact. Non-perceptual technologies will still be mentioned in related works as these are studied and used along-side the Microsoft Kinect. Thus, while several studies have investigated models and methods in meaningful gestures on screens, gloves, pens, and other non-perceptual technologies that require physical contact, this study focuses on defining a set of "in-air" gestures with attention to making a natural and intuitive way of interacting with home automation systems. Although this is not an exhaustive look at literatures regarding Microsoft KINECT and the technology behind it, the survey or related works provides a practical mean to understand how the device work, and its application in research.

With the invention of Microsoft Kinect sensor, high-resolution depth and visual (RGB) sensing has become more available for widespread use [15]. The complimentary nature of the depth and visual information provided by the sensor opens up new frontiers to solve fundamental problems in machine vision. Though originally perceived to revolutionized entertainment as a control-free interface for XBOX, Kinect's impact has extended far beyond the gaming industry [16]. Many researchers have utilized the device to develop creative ways to interact with machines and perform different tasks - Microsoft calls this the "Kinect Effect." In 2012, the tech giant released the first version of the Kinect Software Development Kit (SDK) for Windows, which undoubtedly amplified the Kinect Effect to reach more practitioners and developers from the fields of computer science, electronics engineering and robotics, thus transforming human-computer interaction in multiple industries [16]. The following is a survey of studies published on Microsoft Kinect technology evaluation and its applications.

The Kinect found its way outside the living room to the other places inside the house. Panger [17] studied the problem of people who want to flip through recipe books, change music, or set a kitchen timer even with hands messy from cooking or baking. Another application that uses Kinect is the Ambient Wall [18], a smart home system that allows users to control the television, air conditioning, and others through an interface projected on a wall. Hands-Up [19] uses the device with a projected user interface on the ceiling surface, where users lying in bed put their hands up to control devices. You, et. al. [20] integrated Kinect with and Arduino creating an immersive ambient entertaining environment in automating parties. The system is responsive and sensitive to human activity such as gestures, body movement and facial expressions. 


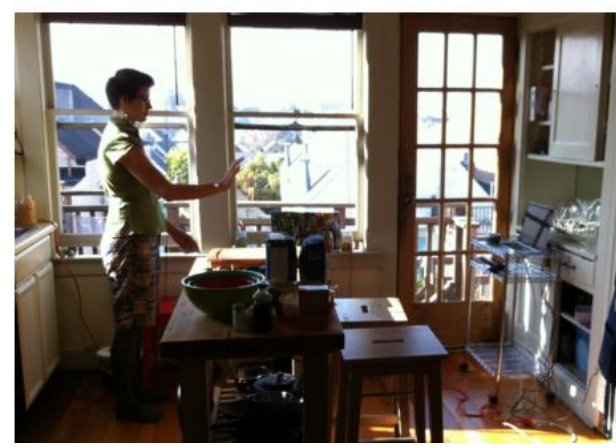

(a)

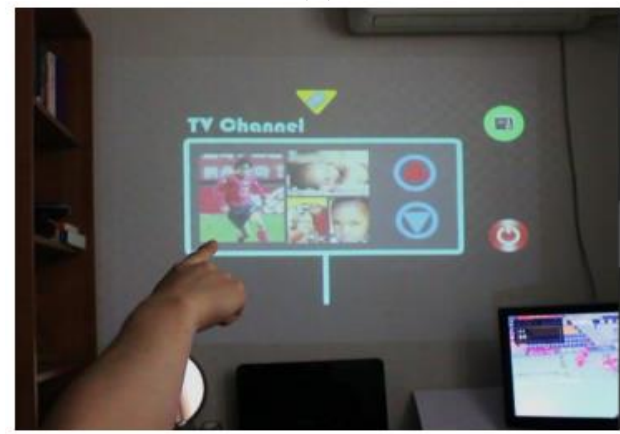

(b)

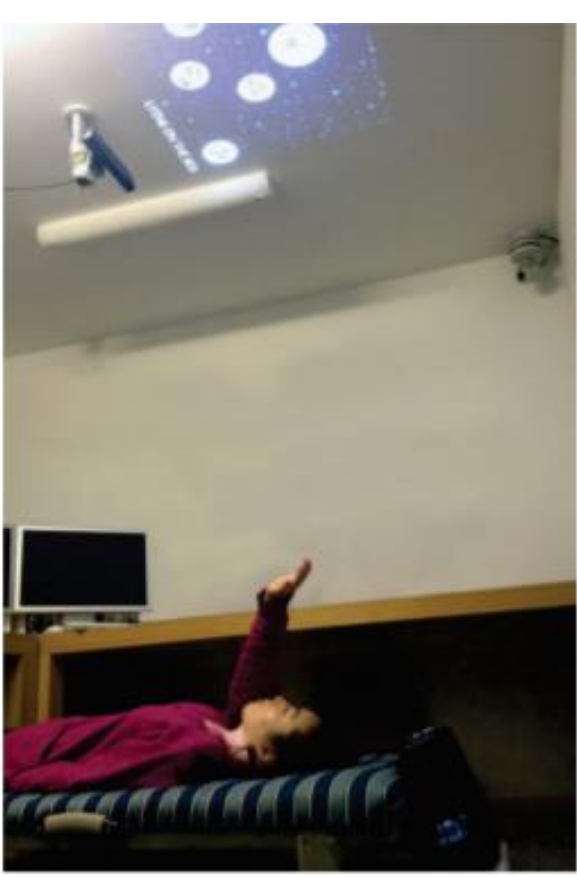

(c)

Fig. 4 Photos of Kinect sensor application at home, (a) in the kitchen, (b) the ambient wall, and (c) bedroom ceiling

Using Kinect as an assistive technology at home was also popular especially in terms of activity monitoring, tele-rehabilitation, and elderly care. Lin, et. al. [21] used the highresolution RGB and depth images taken using the Kinect and applied continued deep learning models in neural networks to detect abnormal events to help users avoid injuries from falling. To promote healthier living at home, Zhao \& Lun [22] developed a user activity tracking system using Kinect with sensor inputs and fitness bands for health feedback. The system continuously monitors users and detect bad postures. Logs can be accessed via mobile devices to see their progress.

In a more medical application, Blumrosen, et. al. [23] used the Kinect as a non-wearable sensor to track human activity at home. They extracted Kinect Signatures to differentiate patients for tele-rehabilitation and kinematics therapy. Kinect was also used as a smart home aide to people with disabilities, the differently-abled, and patients with specific needs, for applications such as controlling appliances [24] and interpreting sign language as commands [25]. 
A good number of papers also studied sensor accuracy and enhancement in technology for the Microsoft Kinect. Early adopters of the device laid down the foundations to further researches in the area. Microsoft Senior Expert on Machine Vision, Zhang [16][26][27] with his colleagues, studied the device and improved its hand gesture recognition algorithm using the Finger-Earth Mover's Distance. This enhanced the sensor's accuracy, efficiency, robustness to articulation, distortions, scale changes and orientation. In addition, Cook, et. al. [28] investigated the use of the Kinect as a close-range hand and fingertip detector. They were able to recognize hand signals which were quite unconventional considering the device is made to detect skeletal structure of the whole body for poses and movements. Also, Wu, et. al [29] believes that gestures are supposedly both natural and intuitive, thus their group developed a one-shot gesture recognition learning system with the Kinect sensor. For this study, user defined leaning and testing sets were evaluated using the Chalearn Gesture Challenge.

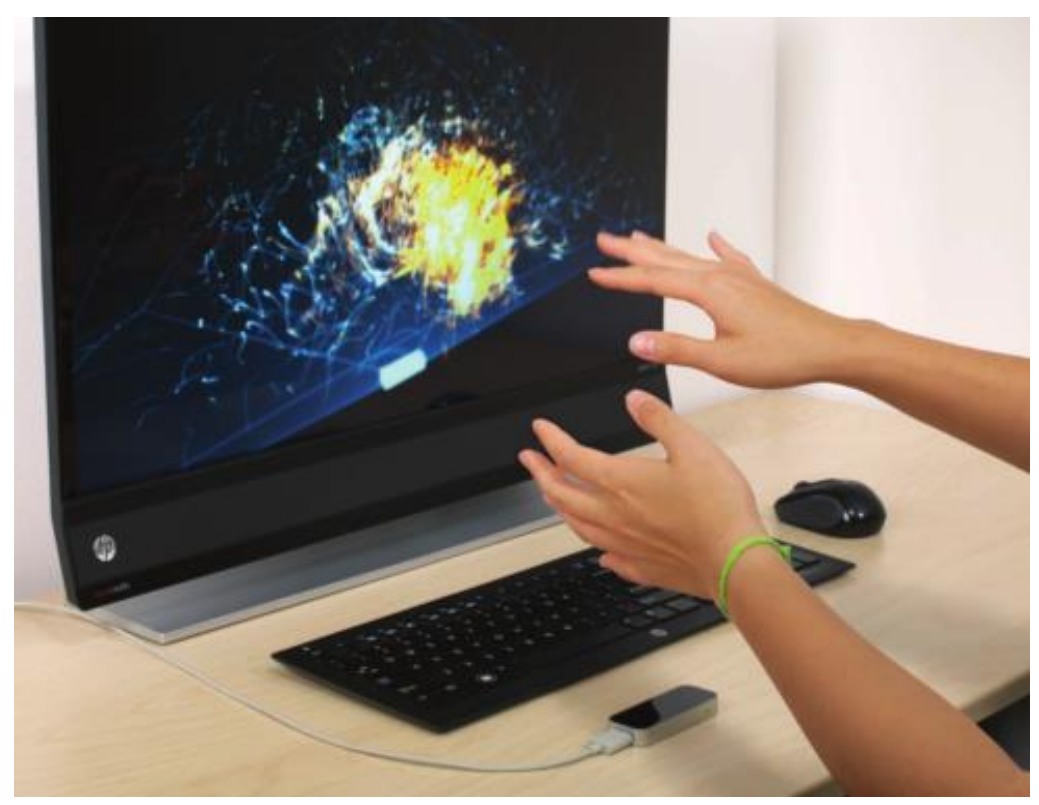

Fig. 5 The Leap Motion Controller

The LEAP Motion controller is a small peripheral that plugs into USB port and sits in a desk or table in front of a computer. Using two cameras to capture motion information and three infrared LEDs as a light source, the system tracks the movements of hands, fingers, finger joints, and several other objects in an area of approximately $60 \mathrm{~cm}$ in front of, to the side of and above the device. Compared to the Kinect, which tracks large full-body movements, the 
LEAP Motion Controller detects small motions and can be accurate to within 0.01 millimeters.

Some notable studies that used the device include the works of Seixas, et. al [30] which characterized the LEAP Motion movements in 2D pointing tasks in comparison to the mouse and touchpad. This research used the ISO 9241-9 for multi-dimensional tapping test and assessed the usability of the device as an alternative to traditional computer input peripherals. Now as a digital hand glove alternative, Cavalcanti, et. al. [31] proposed an experiment to verify the use of the LEAP Motion controller for hand and write rehabilitation. Similarly, Gunawardane \& Medagerada [32] compared inputs from the device with a digital hand glove for movements such as yaw, pitch, and roll. Expectedly, the LEAP Motion succeeded with flying colors. To analyze precision and reliability, Guna, et. al. [33] evaluated the performance of the LEAP Motion controller in both static and dynamic measurements, with different tracking objects for multiple configurations. For static measurements, the standard deviation was less than $0.5 \mathrm{~mm}$, which increased when moving away, while the dynamic measurement shows a significant drop in accuracy for sampled taken more than $250 \mathrm{~mm}$ above the controller. In addition, Siegl et. al [34] suggested the LEAP Motion control is limited by the software rather than its hardware components as a result of their study on the usability of recent consumer grade 3D input devices.

On the more practical applications, Ameur, et. al [35] developed a comprehensive LEAP Motion database for hand gesture recognition. This was used for medical visualization while focusing on user satisfaction with movements such as click, left and right rotate, increase and decrease contrast, zoom in and out, move left and right, previous and next. As a popular case study, LEAP Motion was used to interpret sign language both in Indian Sign Language [36] and American Sign Language (ASL) [36], including manual signs and finger-spelling [37] with great accuracy. In addition, a novel method to tracking movements of the human hand, Ponraj \& Ren [38] used the LEAP Motion control with flex sensors to follow finger tips. And as a recent development that the LEAP Motion company wants to venture in, the device is introduced as a Virtual Reality (VR) or Augmented Reality (AR) controller, such as those in the virtual museum [39] and VR bulb switches control [40]. 
Aside from published papers on the technology and applications of Microsoft Kinect and LEAP Motion controller respectively, there have also been related works on both comparison and integration of these two devices. Vokorokos, et. al [41] studied the gesticulation efficiency of the Kinect, LEAP Motion and Myo Armband, a non-perceptual technology with muscle contraction sensor. This study surveyed 50 different measurements for movement and concluded that LEAP Motion performs well for pointing, and clenching the fist, the Kinect for waving, hand rotating for the Myo Armband. Similarly, Cabreira \& Hwang [42] analyzed 15 more mid-air gesture across the three platforms. Lastly, two studies by Marin, et. al [43][44] explored the combined use of the Kinect and LEAP Motion control for an optimized accuracy in hand gesture recognition. For this example, they used a machine learning approach to recognize the American Manual Alphabet to show very high accuracy in real-time.

Both technologies have their own strengths and challenges in terms of the depth of technology and advancement in applications. As presented in this chapter, the survey of related works and published literature on the research viability of these devices proved exciting potential for Microsoft Kinect and LEAP Motion as gesture control technologies suitable for the implementation of this study.

As presented in this section, the survey of related works and published literature regarding the research viability of such devices proved exciting potential for the Microsoft Kinect as a gesture control technology suitable for the implementation of this study. Thus, while several studies have showed the potential of motion capture sensors outside of gaming and entertainment, in areas such as tele-rehabilitation, aid for the elderly and people-withdisabilities, and digital interactions, this study investigates on the use of the Microsoft Kinect to interact with home automation systems to attain a higher uptake for smart home technologies towards promoting sustainability.

\subsection{Gesture Interaction \& Socio-Technical Aspects}

The use of gestural interaction, being frequently used in everyday social life, is considered intuitive in human communication. When addressing the naturalness of interaction (i.e. 
intuitive, easy to learn) it is indispensable to consider social and cultural aspects of a target audience when defining a gestural vocabulary - thus meaningful gestures that do feel natural, intuitive, and easy to learn.

Developers and researchers try to provide solutions to users through complex computational means, as seen with improved accuracy, efficiency, and robustness in the case of Microsoft Kinect, aside from the technical aspects [16][45][26] however, the social sphere needs to be considered as well. With this in mind, Correia, et. al. [14] proposed a framework to identify and discuss the challenges of different forms of interaction with technology considering socio-technical aspects in an integrated manner. The framework consists of the main dimensions: home automation systems, gesture interaction, and human. The concentric organization of these three suggests their interdependency in a triadic relationship [14]. As shown in Fig. 6, each aspect is represented by a dashed ellipse and has interactions with the three dimensions.

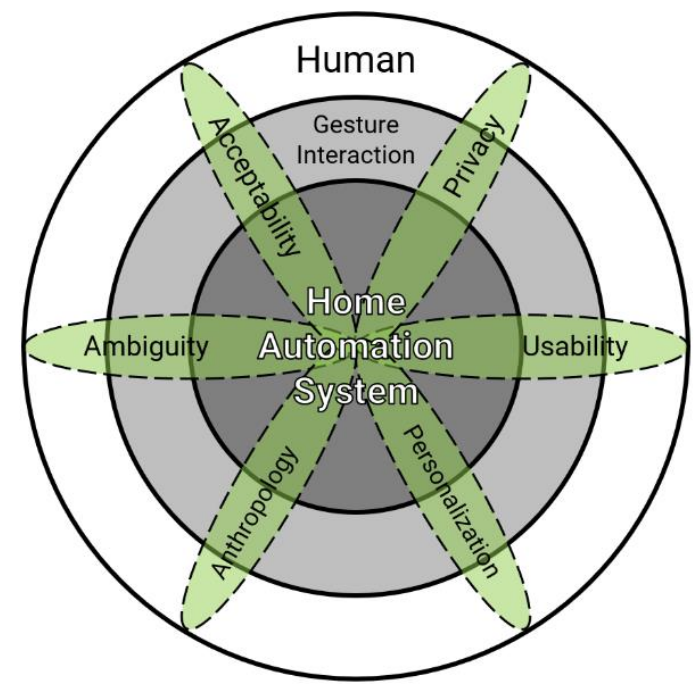

Fig. 6 Framework of Socio-technical Aspects for Gesture Interaction

Therefore, while several studies have looked into reliability, accuracy, and efficiency in using the Microsoft Kinect for gesture recognition, this study will conduct a socio-technical study under three specific aspects to attain a level of acceptability, ease of use, and gesture anthropology and better understand the relation of gesture control and home automation systems. 
- Acceptability - level of user's positive response towards a new technology or innovation. This aspect will be guided by the Technology acceptance model (TAM) proposed by Davis, et. al [46]. Factors such as Perceived usefulness (PU) and Perceived ease-of-use (PEOU) will be measured to come up with the level of acceptability.

- Usability or General ease-of-use - measure of learnability, memorability, errors, satisfaction and overall comfort of the user towards the technology. These main topics were suggested by Nielsen [47] to understand how usability interplays with gestural interaction.

- Culturability or Gesture Anthropology - suggestive measure of naturalness or intrusiveness of interaction with the home automation system for people coming from different cultural or ethnological background. Researchers are still trying to understand how the gestures are influenced by culture [14]. Although this detail might seem irrelevant for the definition of gestures, it might very well influence whether a certain gesture is considered appropriate in a certain cultural context.

- Personalization - customization is related to the huge amount of information that needs to be managed simultaneously [14]. This is to support versatility of gestural commands for different solutions.

- Ambiguity - to enable natural and meaningful interactions, the ambiguity of gestures in the real world needs to reduce for interacting in the virtual world [14]. Gestures need to be cohesive and consistent in their meanings.

- Privacy - context of home requires a number of concerns about privacy because it refers to intimate environment in which the lack of privacy can have negative effects on social relationships among residents [14]. 


\section{SYSTEM DESIGN AND DEVELOPMENT}

This chapter will discuss stages 2 to 4 of the research workflow. As such, it will be further divided into six other sections: (a) Gesture Dictionary, (b) System Architecure, (c) Technical Specifications, (d) Gesture Recognition, (e) Likert Items for Testing, and (f) Ethics in Research. These sections will tackle topics regarding the technical implementation done towards the pursuing the research goals.

\subsection{Gesture Dictionary}

Nine gestures were defined as meaningful actions to build the dictionary for HAS gesture interactions. From this set, 8 gestures correspond to controlling 4 different smart home devices, and 1 auxiliary gesture. All nine gestures follow a specific gesture style based on the classification of gesture-based human computer interactions by Karam, et. al [13] and as shown in Fig. 3. Figure 4 and Table 4 below present the range of gestures and the developed gesture dictionary respectively.

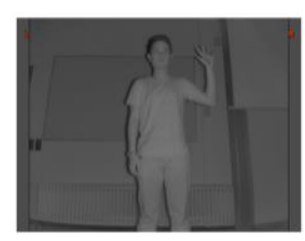

HAND OPEN

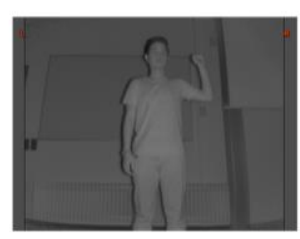

HAND CLOSED

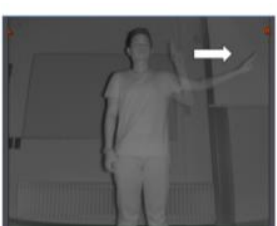

SWIPE RIGHT

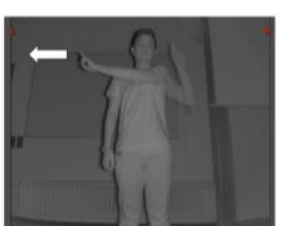

SWIPE LEFT

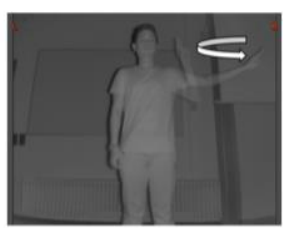

SWIPE AROUND

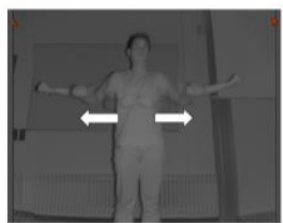

ARMS OPEN

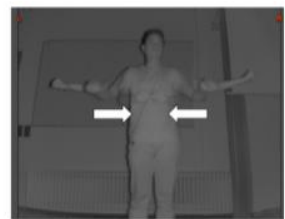

ARMS CLOSED

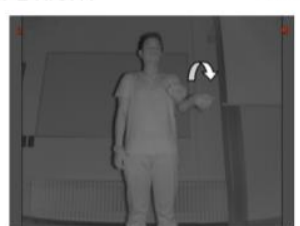

TURN CW

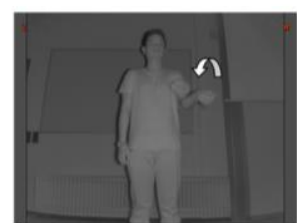

TURN CCW

Fig. 7 Gesture dictionary visualized with Microsoft Kinect (Summary) 
Table 4 Gesture Dictionary for HAS

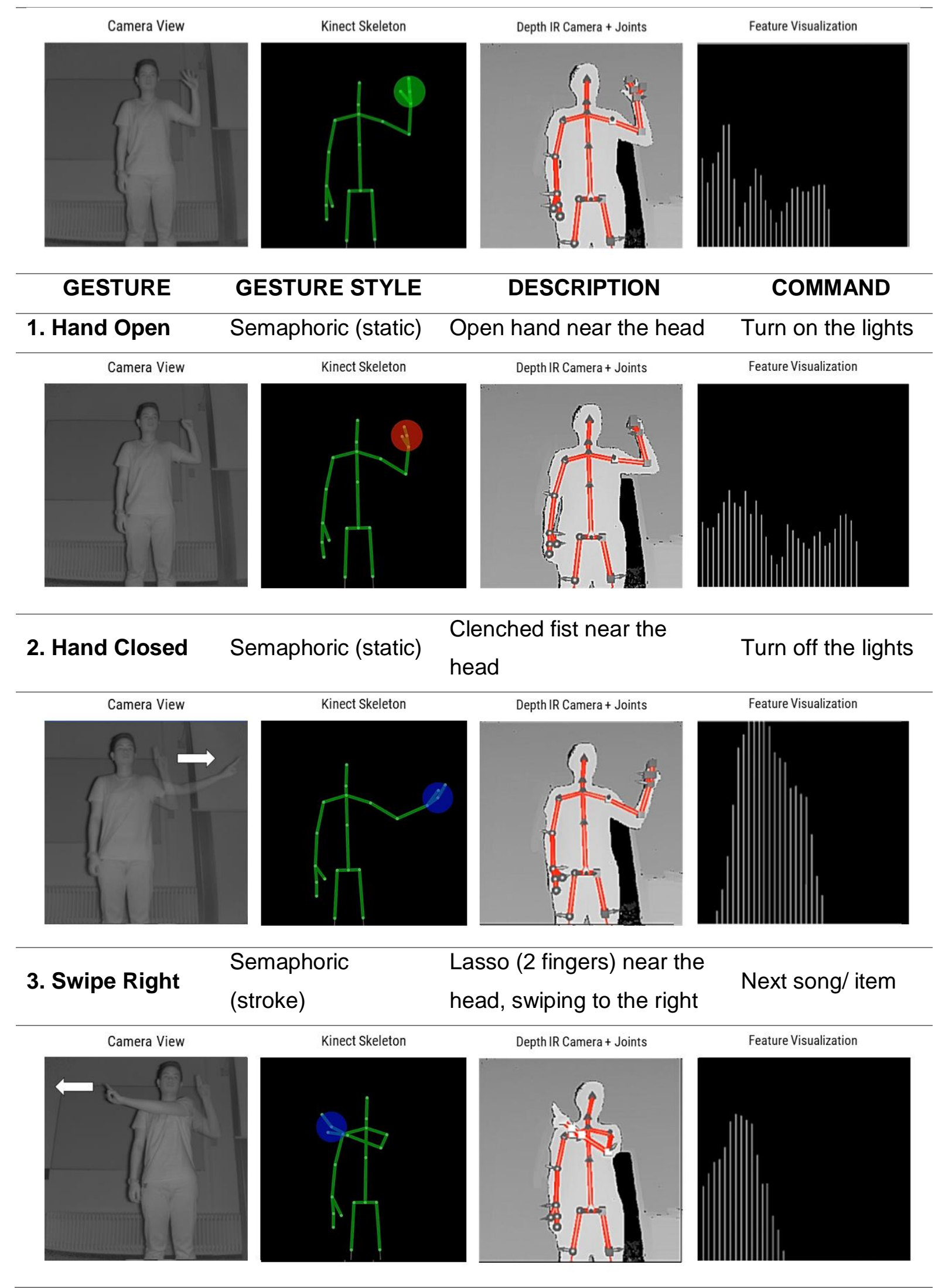



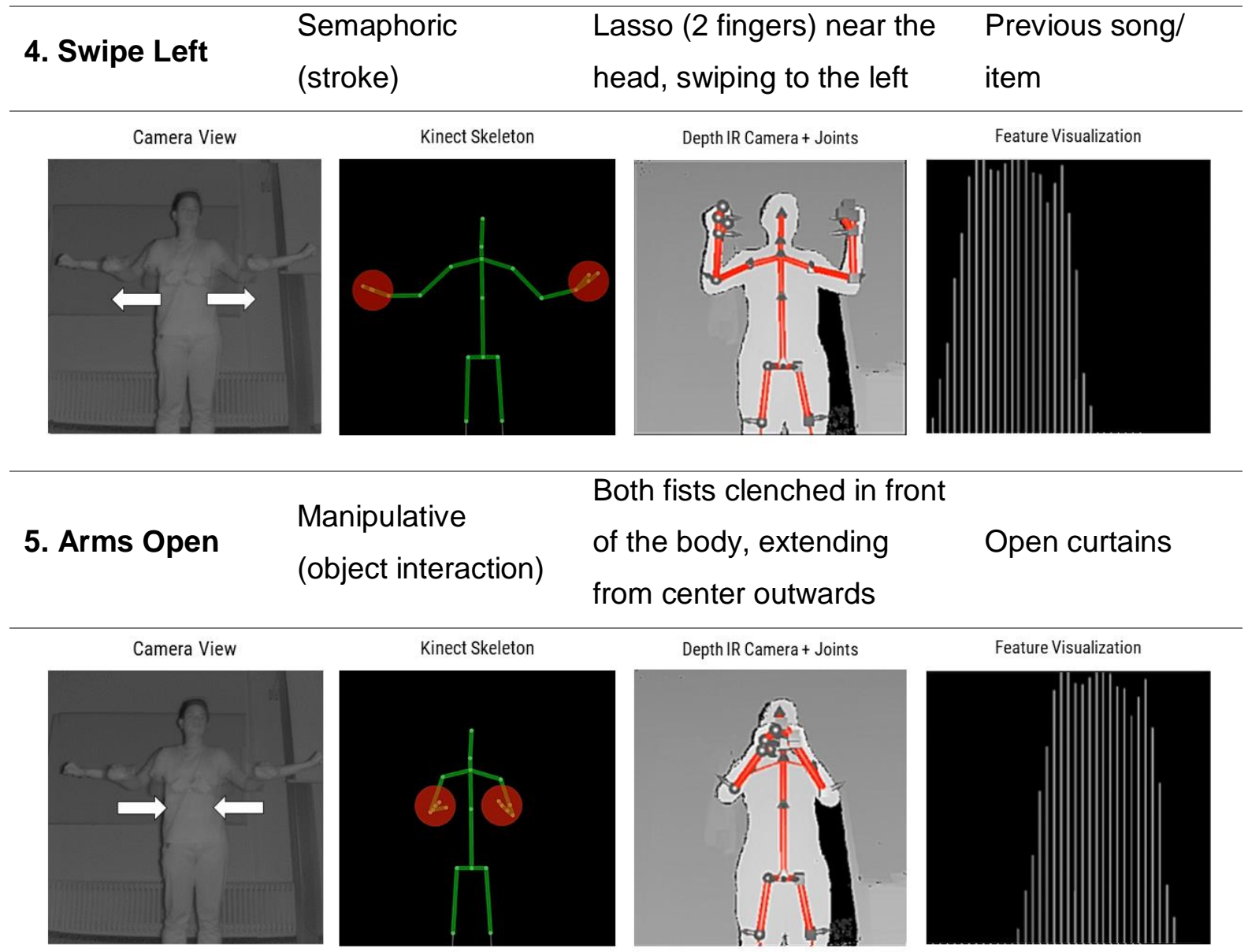

\section{Arms Closed $\quad \begin{aligned} & \text { Manipulative } \\ & \text { (object interaction) }\end{aligned}$}

Both fists clenched, arm level away moving towards Close curtains the center of the body
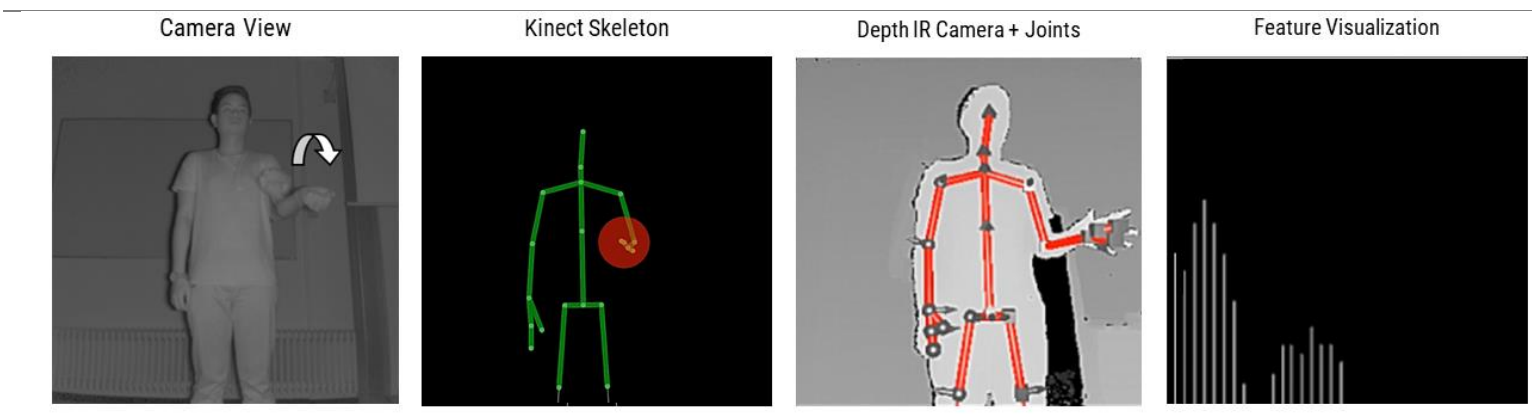

\section{Turn CW \\ Manipulative (object interaction)}

Clenched fist at arm level, turn wrist clockwise (to the Heater value up right) 


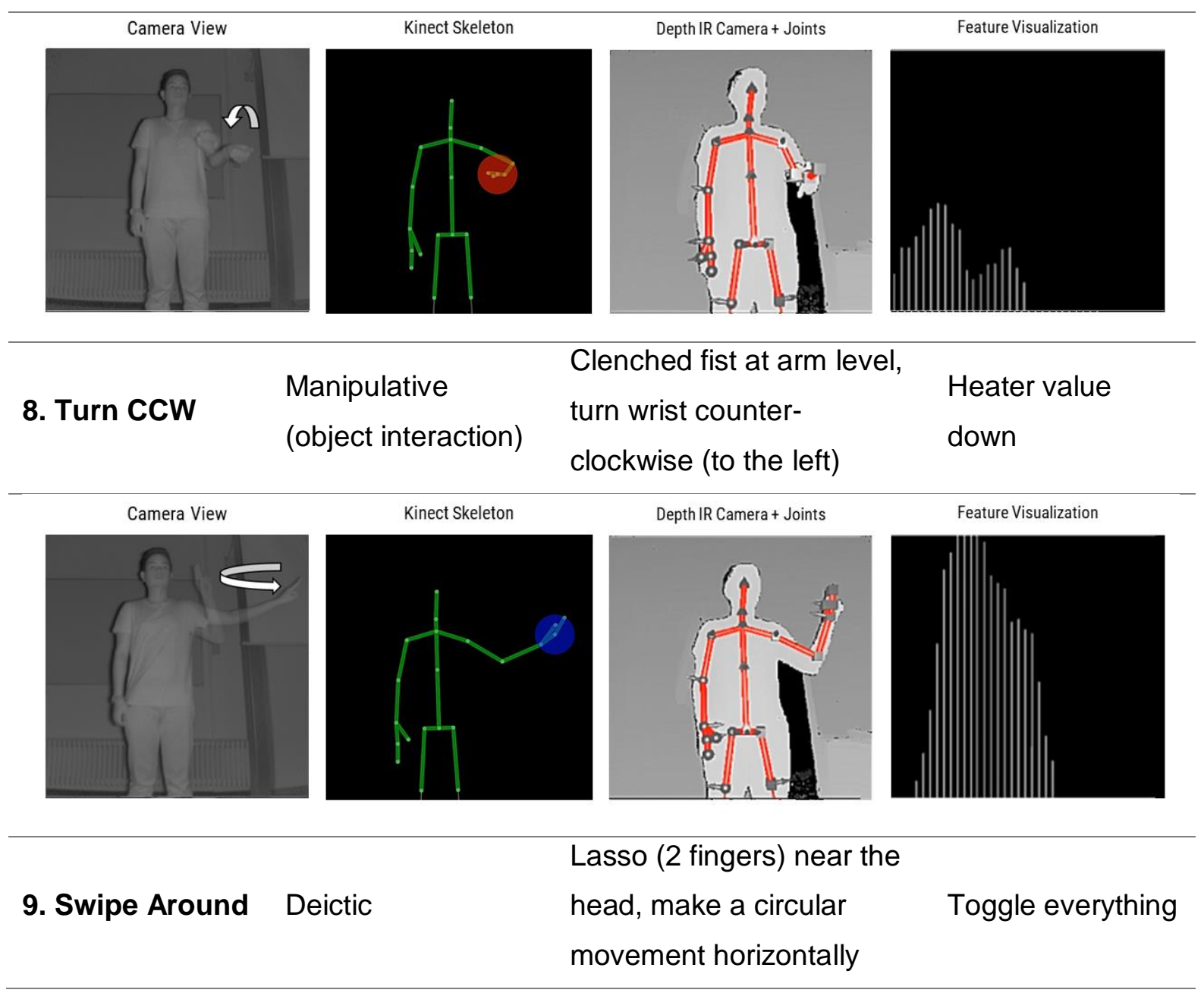

\subsection{System Architecture}

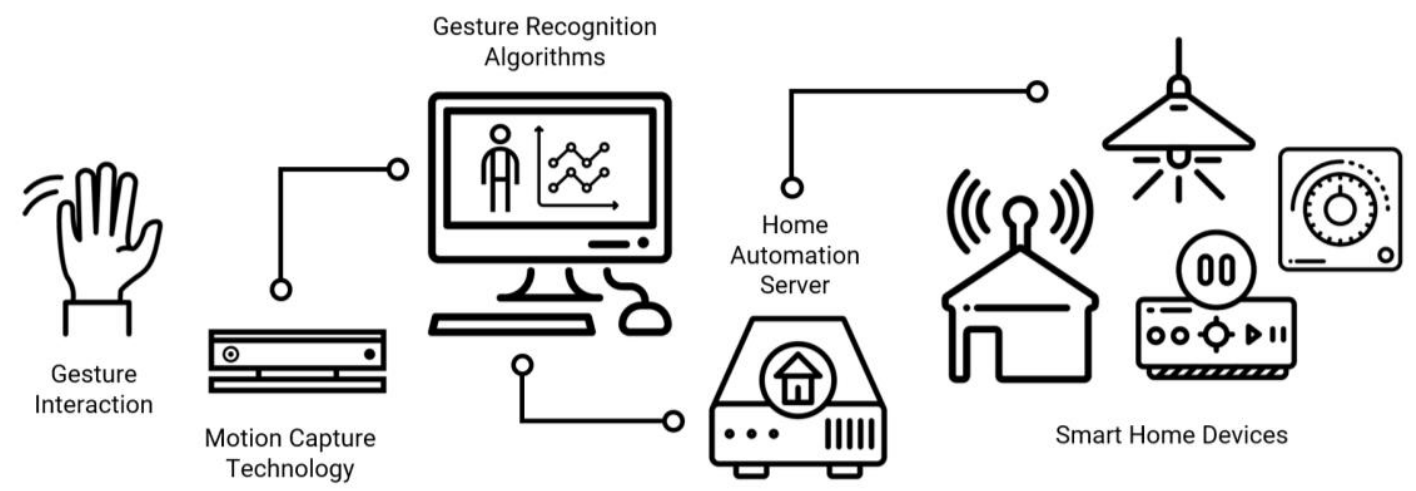

Fig. 8 System architecture diagram for HAS gesture interaction 
Figure 8 describes how the perceived system works. The gesture will be taken in by the motion capture technology, the input feed will go into the gesture recognition algorithms for detection and labelling, then controls will be sent out to the home automation server through a web socket. This then will control the corresponding smart home device as commanded by the gesture.

\subsection{Technical Specifications}

The Microsoft Kinect offers high-quality skeletal tracking and recognition. As presented in Fig. 9, the sensor consists of a color camera (RGB), depth sensor with infrared (IR) camera and projector, and a built-in microphone array. It can track up to six bodies simultaneously with 25 skeletal joints each, and three recognized hand states: open (palms out), closed (clenched fist), and lasso (2 fingers). The Kinect Windows SDK was used to develop C\# software for the use of this study. In addition, the Kinect Studio v2.0, and Visual Gesture Builder were utilized for motion capture and labelling. Fig. 10 shows the joint map for Microsoft Kinect, an important information for consideration during developing gestures.
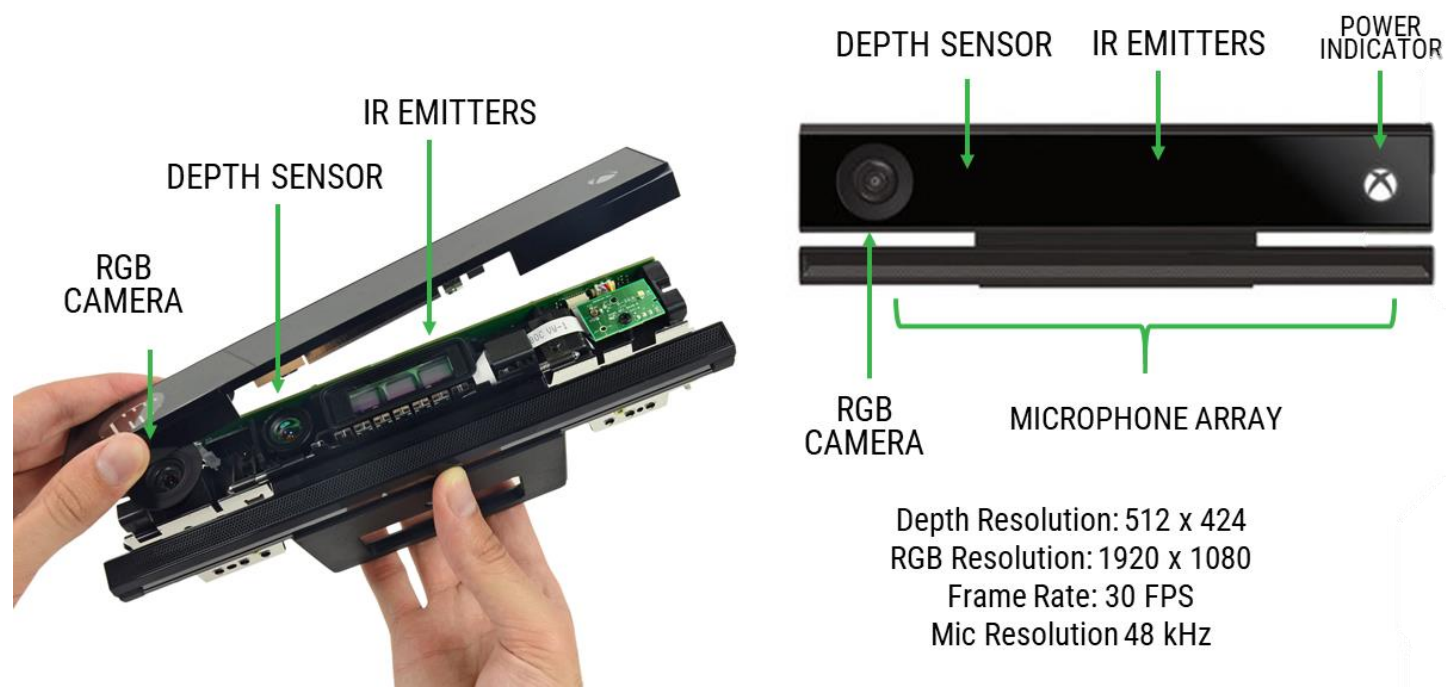

Fig. 9 Microsoft Kinect Parts and Specifications 


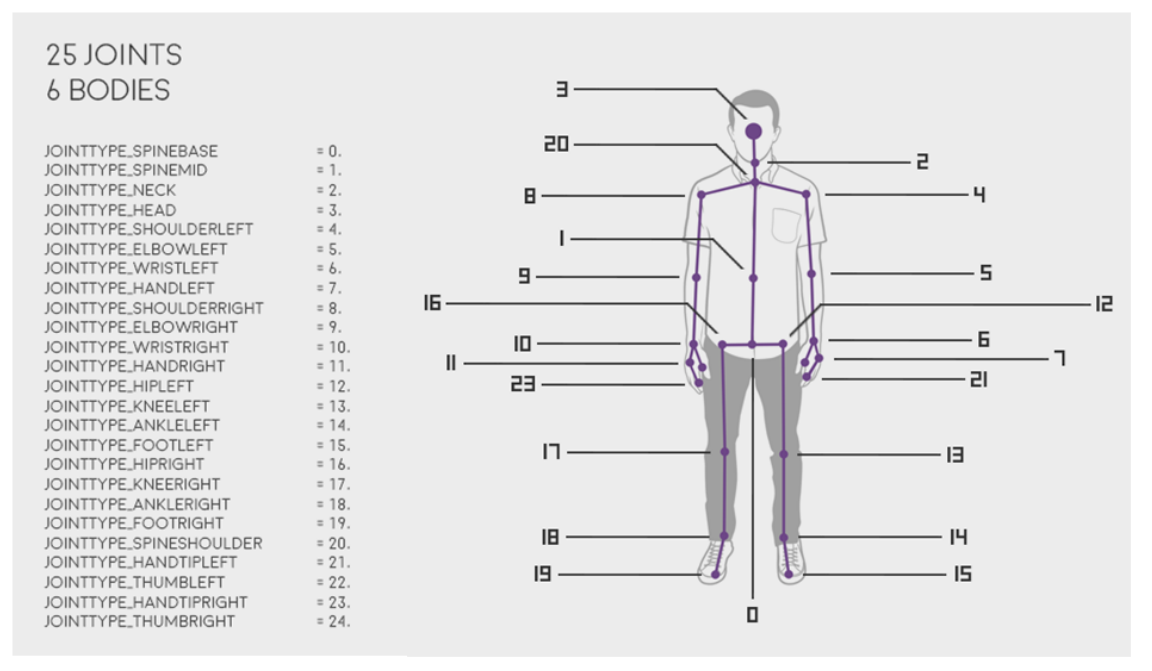

Fig. 10 Microsoft Kinect Joints Map

The Leap Motion Controller represents a major leap in input technology that could, with its enhanced interaction possibilities, trigger a new generation of far more useful 3D displays and possibly surpass the mouse as a primary input device [33]. The Leap Motion Controller, as shown in Fig. 11, uses infrared (IR) imaging to determine the position of predefined objects in a limited space in real time. It recognizes hands, fingers, and tools, reporting discrete positions, gestures, and motion. The controller's field of view is an inverted pyramid centered on the device. The effective range of the controller extends from approximately 25 to 600 millimeters above the device [33]. Fig. 12 presents the joint map for LEAP Motion control. In comparison to Microsoft Kinect, hand and finger joints are more detailed.
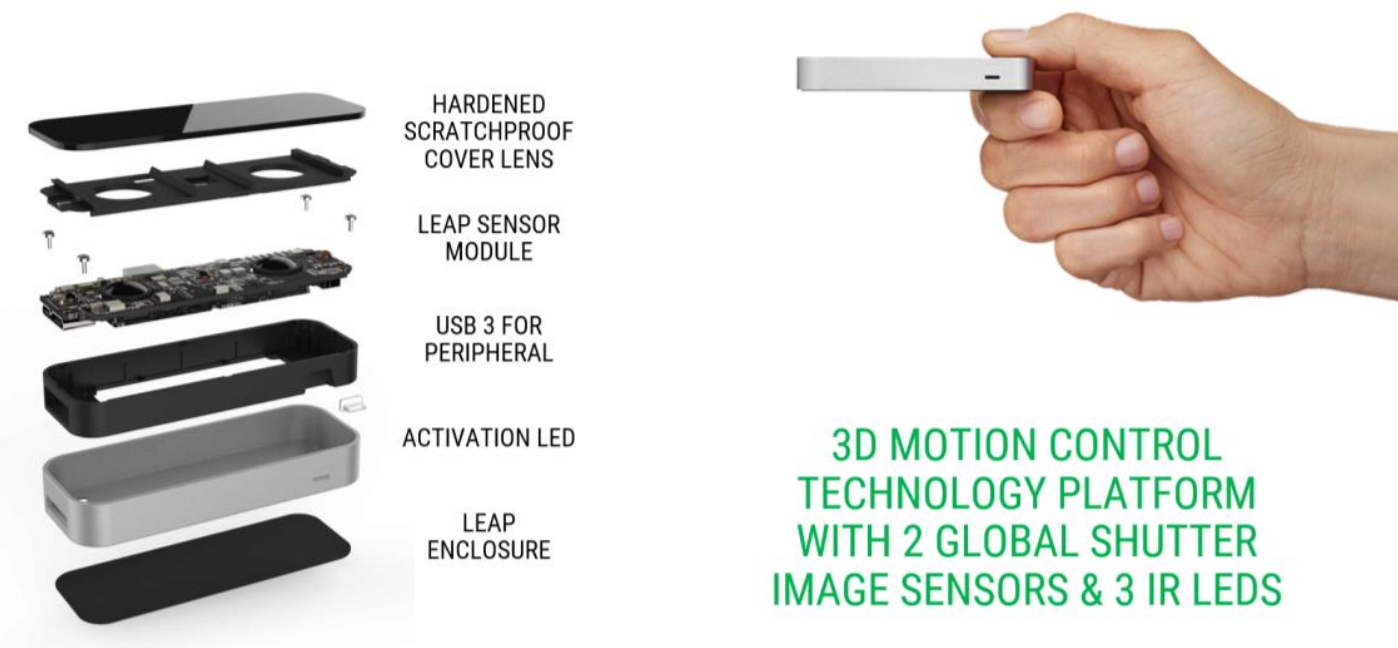

Fig. 11 LEAP Motion Control Parts and Specifications 

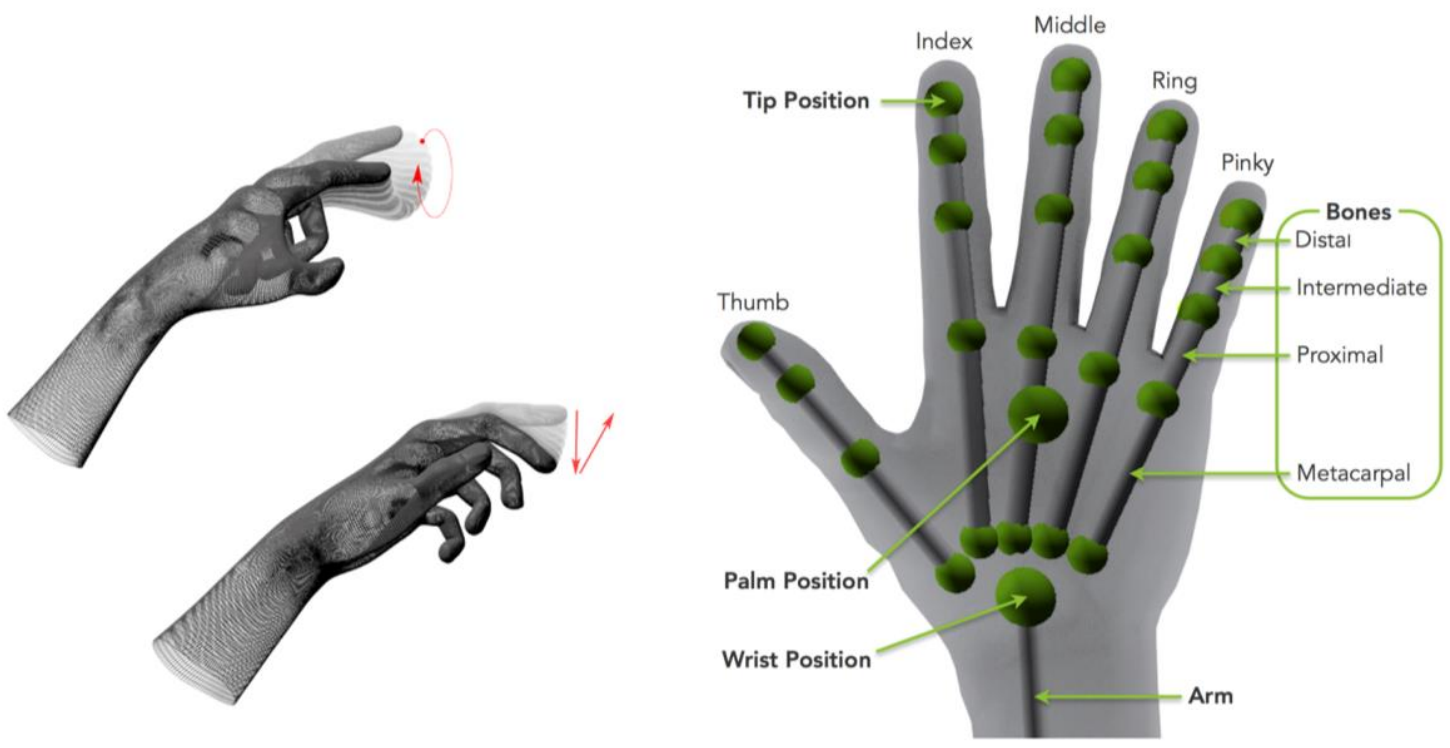

Fig. 12 LEAP Motion Control Joints Map

Home Assistant and FHEM were used as open-source HAS platform and server while smart home devices such as HomeMatic, Conrad, RWE Smarthome actuators, Amazon Echo speakers, and Philips Hue lightbulbs were integrated for the smart home devices as presented in Fig 13.
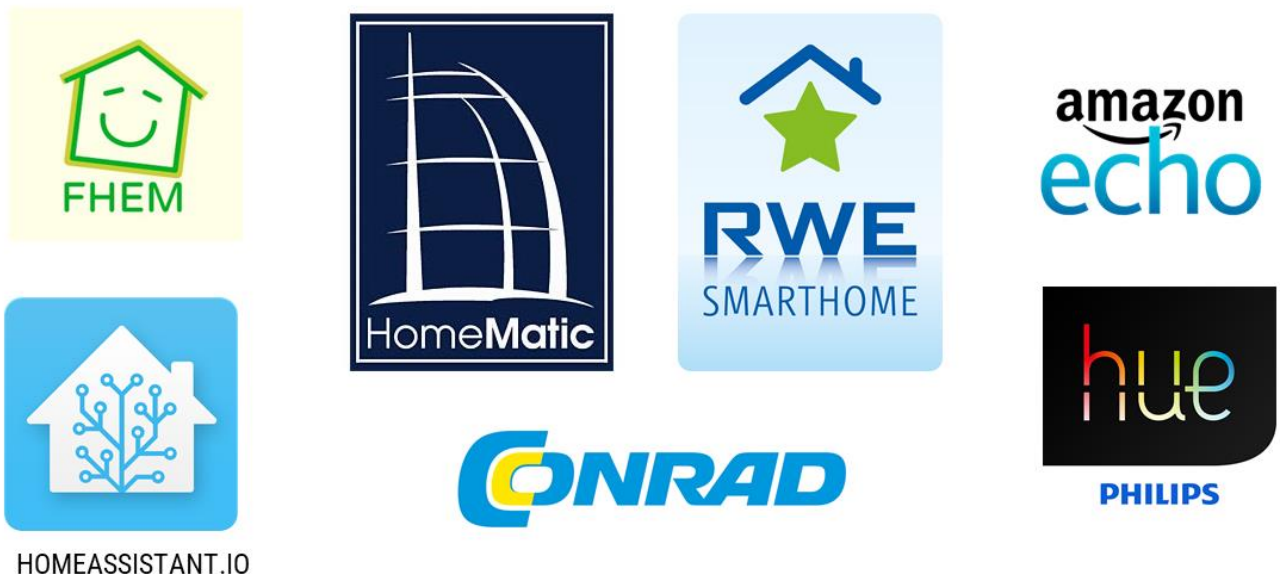

PHILIPS

Fig. 13 Smart home devices (servers \& actuators) 


\subsection{Gesture Recognition}

Based the methodology presented by Zuffrey, et. al [32], the machine learning approach was used and adapted to fit the set of software tools and requirements from the capture technologies. The gesture recognition process followed the Machine Learning approach that is divided into six steps for all nine gestures.

As presented in Fig 14, first was (1) data acquisition with gesture recording using the Kinect Studio v2.0 then each .xref file was run through (2) pre-processing for compression and optimization. Now using the Visual Gesture Builder shown in Fig. 15, (3) features were extracted after proper labelling, (4) training and test sets were separated with training sets were put into (5) post processing as shown in Fig. 17, with two active algorithms: AdaBoost Trigger (discrete gestures), and Gesture Dictionary for HAS RFRP Progress (continuous gestures), then lastly creation of the (6) classification model as shown in Fig. 16.

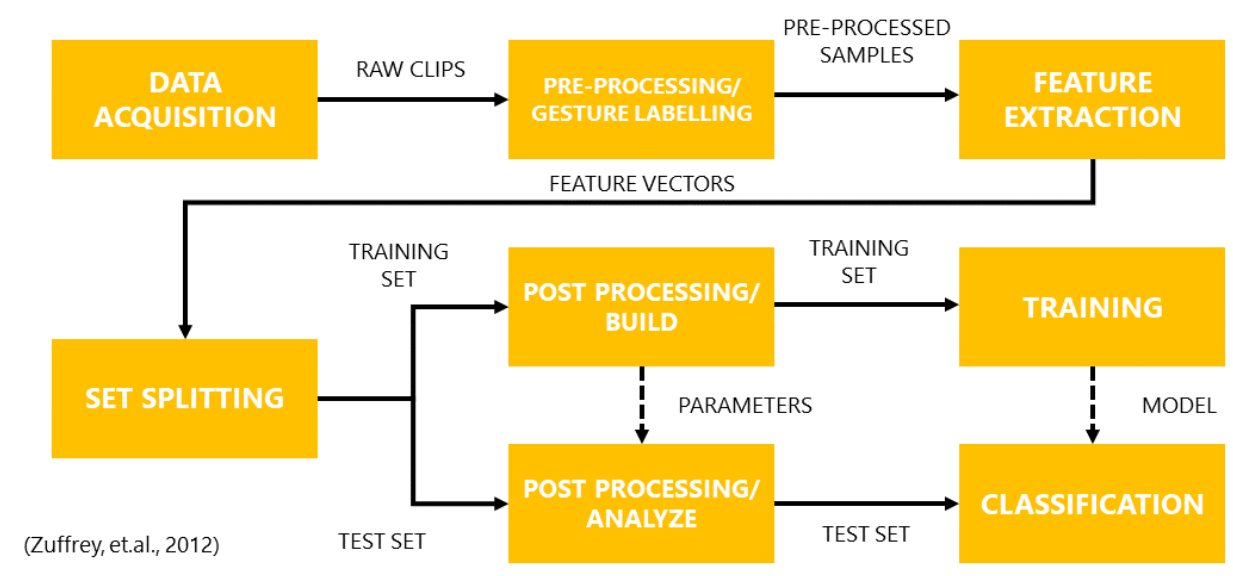

Fig. 14 The machine learning approach 

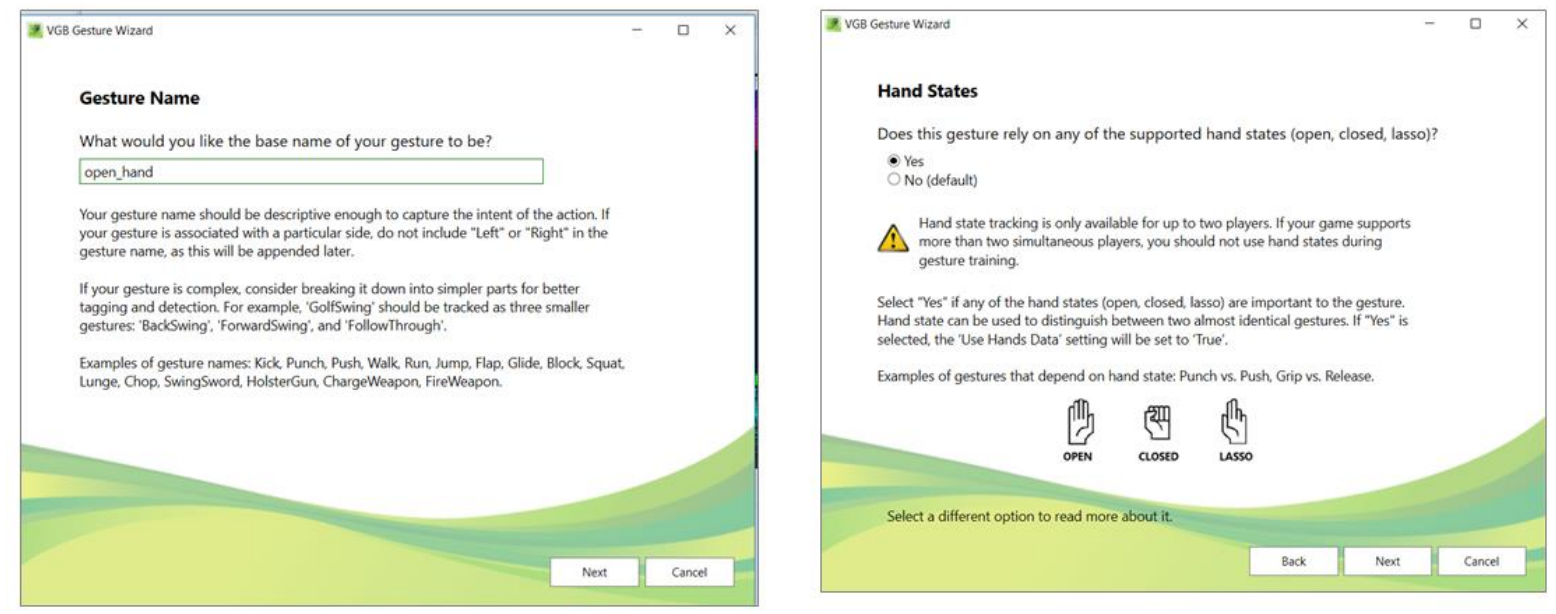

Fig. 15 Using the Visual Gesture Wizard to initiate gesture recognition

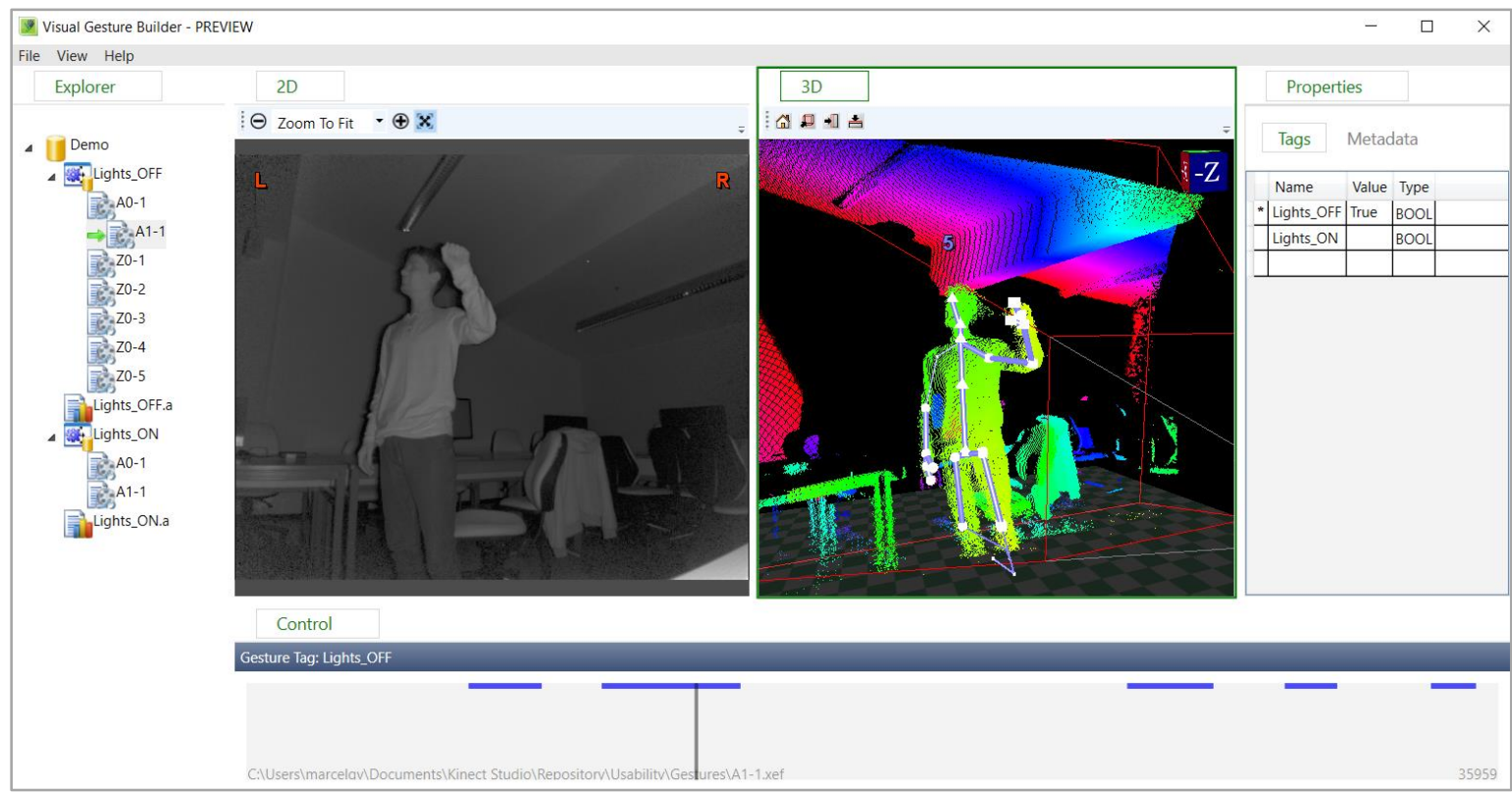

Fig. 16 Labelling gestures using Visual Gesture Builder

The gesture recognition process followed the Machine Learning approach that is divided into six steps.

1. Data acquisition with gesture recording using the Kinect Studio v2.0

2. Each .xref file was run through pre-processing for compression and optimization.

3. Using Visual Gesture Builder, features were extracted after proper labelling,

4. Training and test sets were separated

5. Training sets were put into post processing with two active algorithms: AdaBoost Trigger (discrete gestures) and RFR Progress (continuous gestures)

6. Classification model are created. 

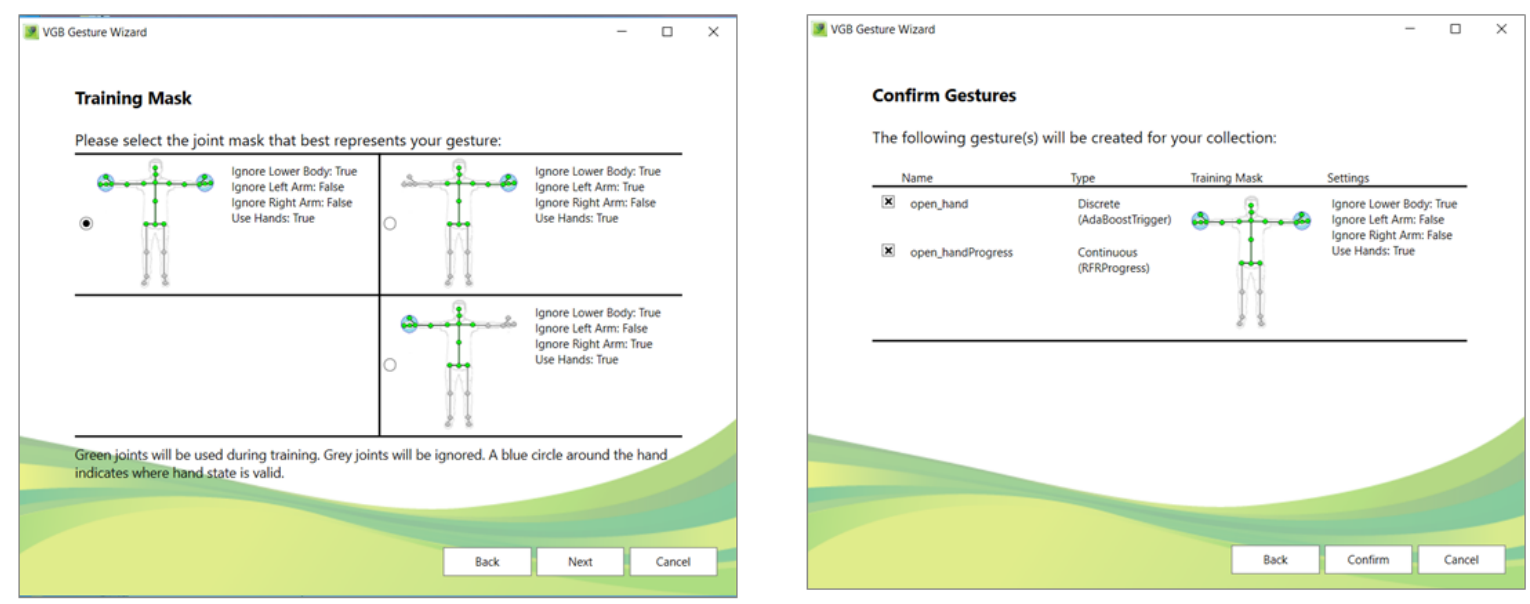

Fig. 17 Setting up masks for post-processing (a) AdaBoost, and (b) RFR Progress

A sample features are presented in Appendix 1 at the end of this report. This shows the 38 different features classified in a given model gesture.

\subsection{Likert Items for Testing}

Among the six socio-technical aspects proposed by Correia, et. al [14], acceptability, easeof-use, and capturability will be used to assess the gesture interaction artifact to gauge a level of adaptability towards a higher uptake of home automation systems.

Likert-type scale or rating scale is a psychometric tool to gauge someone's level of agreement or disagreement on a symmetric agree-disagree scale. A Likert scale is the sum of response on several Likert items - series of statements. This range captures the intensity of their feeling for a given item. The Likert items will be categorically divided into these three socio-technical aspects with their following heuristics. Each set will also correspond to different parts during the public testing as show in Fig. 18. The Likert items in Table 5 will correspond to the questions asked before the demonstration. Likert items in Table 6 and 8 are the questions asked during the use of the technology. Lastly, Likert items in Table 8 are the questions asked for evaluation after the use of the technology. 

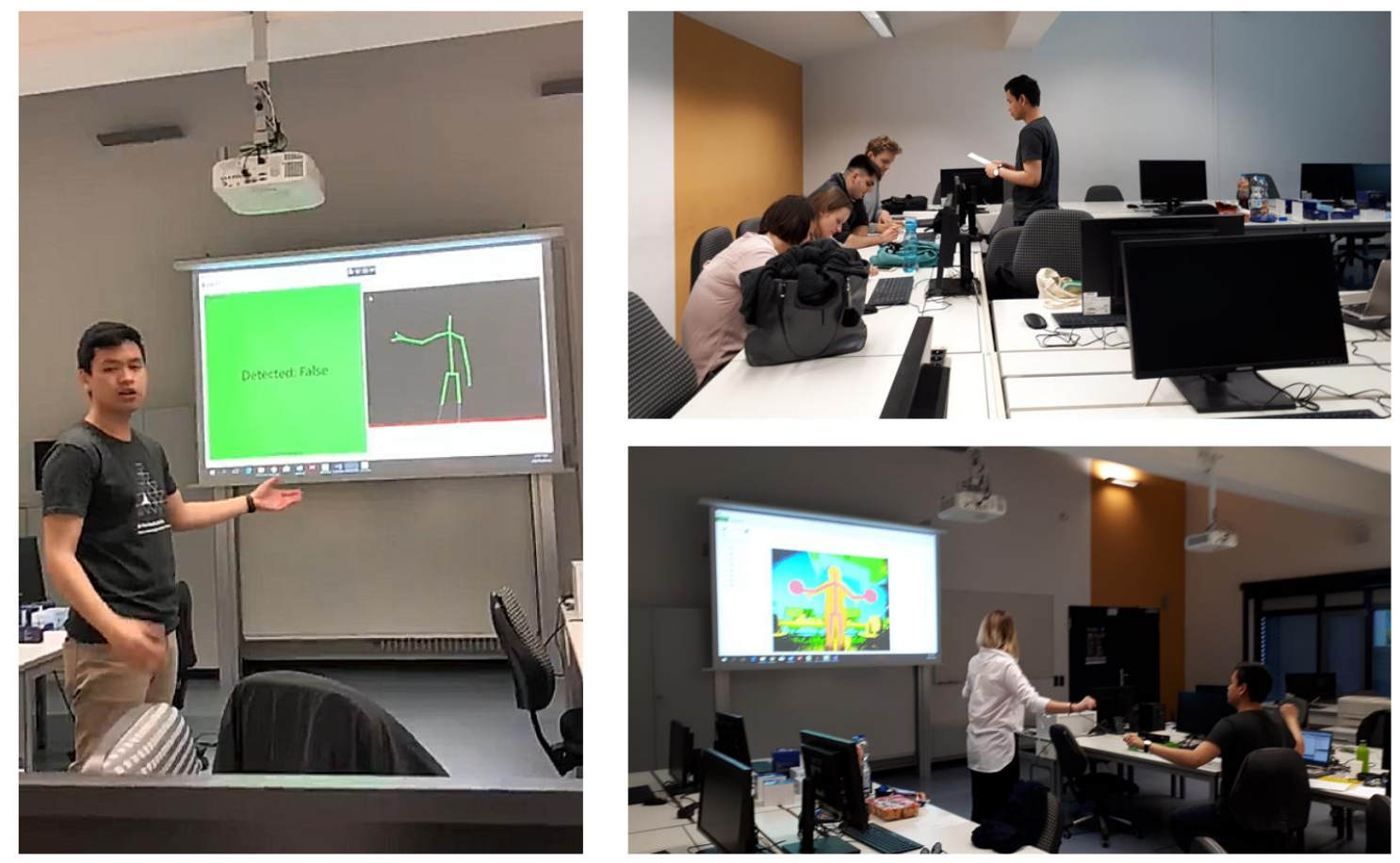

Fig. 18 Photos taken during the demo and testing

Table 5 Likert items for Acceptability

\begin{tabular}{clc}
\hline NO. & \multicolumn{1}{c}{ LIKERT ITEM } & HEURISTICS \\
\hline A1 & $\begin{array}{l}\text { Gesture control will improve my overall } \\
\text { experience with smart homes. }\end{array}$ & $\begin{array}{c}\text { Perceived } \\
\text { usefulness }\end{array}$ \\
\hline A2 & $\begin{array}{l}\text { Gesture control will make interacting with smart } \\
\text { homes easier. }\end{array}$ & $\begin{array}{c}\text { Perceived } \\
\text { ease-of-use }\end{array}$ \\
& I will easily get used to smart home interactions & Attitude towards \\
& with the help of gestures. & using the technology \\
\hline A4 & $\begin{array}{l}\text { Gestures will be a typical way of interacting with } \\
\text { technology in the future. }\end{array}$ & $\begin{array}{c}\text { Behavior towards } \\
\text { intention of use }\end{array}$ \\
\hline
\end{tabular}


Table 6 Likert items for Ease-of-use

\begin{tabular}{clc}
\hline NO. & \multicolumn{1}{c}{ LIKERT ITEM } & HEURISTICS \\
\hline U1 & The gestures are generally easy to remember. & Memorability \\
\hline $\mathbf{U} 2$ & $\begin{array}{l}\text { Most gestures are easy to learn because to } \\
\text { correspond well with the commands. }\end{array}$ & Efficiency \\
\hline $\mathbf{U} 3$ & $\begin{array}{l}\text { The gestures are generally very complex and } \\
\text { complicated to perform. }\end{array}$ & Error \\
\hline $\mathbf{U} 4$ & $\begin{array}{l}\text { It is easy to make errors or mistakes with the } \\
\text { current set of gestures. }\end{array}$ & Satisfaction \\
\hline
\end{tabular}

Table 7 Likert items for Culturability

\begin{tabular}{clc}
\hline NO. & \multicolumn{1}{c}{ LIKERT ITEM } & HEURISTICS \\
\hline C1 & $\begin{array}{l}\text { Using gesture is a natural way of interacting with } \\
\text { smart home technologies. }\end{array}$ & Intuitiveness \\
\hline C2 & $\begin{array}{l}\text { My culture is known to use (hand/body) gestures } \\
\text { as part of everyday communications. }\end{array}$ & Gesture use \\
\hline C3 & $\begin{array}{l}\text { These gestures reflect possible interactions of } \\
\text { people from where I am from. }\end{array}$ & Gesture anthropology \\
\hline C4 & $\begin{array}{l}\text { My cultural background is known to be very } \\
\text { accepting of new technologies/ innovations. }\end{array}$ & Openness to innovation
\end{tabular}

Table 8 Summary and debriefing items

\begin{tabular}{clr}
\hline NO. & \multicolumn{1}{c}{ LIKERT ITEM } & HEURISTICS \\
S1 & $\begin{array}{l}\text { Compared to other media (voice command and } \\
\text { remote controls), I am open to using gestures to } \\
\text { interact with smart homes. }\end{array}$ & $\begin{array}{c}\text { Comparison to other available } \\
\text { mode of interactions }\end{array}$ \\
\hline S2 & $\begin{array}{l}\text { I would buy (or invest to) smart home devices to } \\
\text { control my home. }\end{array}$ & Perceived investment \\
S3 & $\begin{array}{l}\text { I would but (or invest to) gesture technologies to } \\
\text { interact with my smart home. }\end{array}$ & Perceived investment \\
\hline
\end{tabular}




\subsection{Ethics in Research}

As part of the ethical contribution and to maintain a high standard of demo and testing in the context of a Human-Computer Interaction (HCI) research, the risks and benefits of the study was made aware to the participants through an informed consent form. The "Informed Consent Form for Minimal Risk: Classroom Activities/ Projects Involving Human Participants" as appended at the end of this report, was asked to be read, understood, and signed by the participant before going through the demo. The consent form covers the general purpose of the activity, its perceived benefits and risks, confidentiality of data as protected by the newly implemented GDPR EU 2016/679 law, an ethical review of the study, certification of consent by both the participant and the investigator. Two copies of the consent form were made, one for the participant, and a second copy for the investigator. After each demo, the investigator thanks the participant for the time and effort that they had contributed for the study. 


\section{RESULTS}

This chapter will discuss stage 5 of the research workflow. As such, it will be further divided into four other sections: (a) Descriptive Analysis, (b) Socio-technical Evaluations, (c) Cronbach's Alpha, and (d) Analysis of Variance - ANOVA.

\subsection{Descriptive Analysis}

There was a total of thirty-two individual participants from thirteen different countries who contributed time and effort for the success of this study. Among the participants about $60 \%$ are female, and $40 \%$ male. Predominantly, $87.5 \%$ comes from the $13-26$ age group, $9.4 \%$ from 27 - 35 age group, and the remaining part comes from 36 - 50 years old group. It is important to take not that all participants are at least of the age 18 and have legally consented their participant in this study.

As part of the questionnaire, guiding questions were asked to help introduce the topic and the motivation to the participants. Here are some results from the introduction items:

1. Please rate your level of technological aptitude. (Likert scale 1-5)

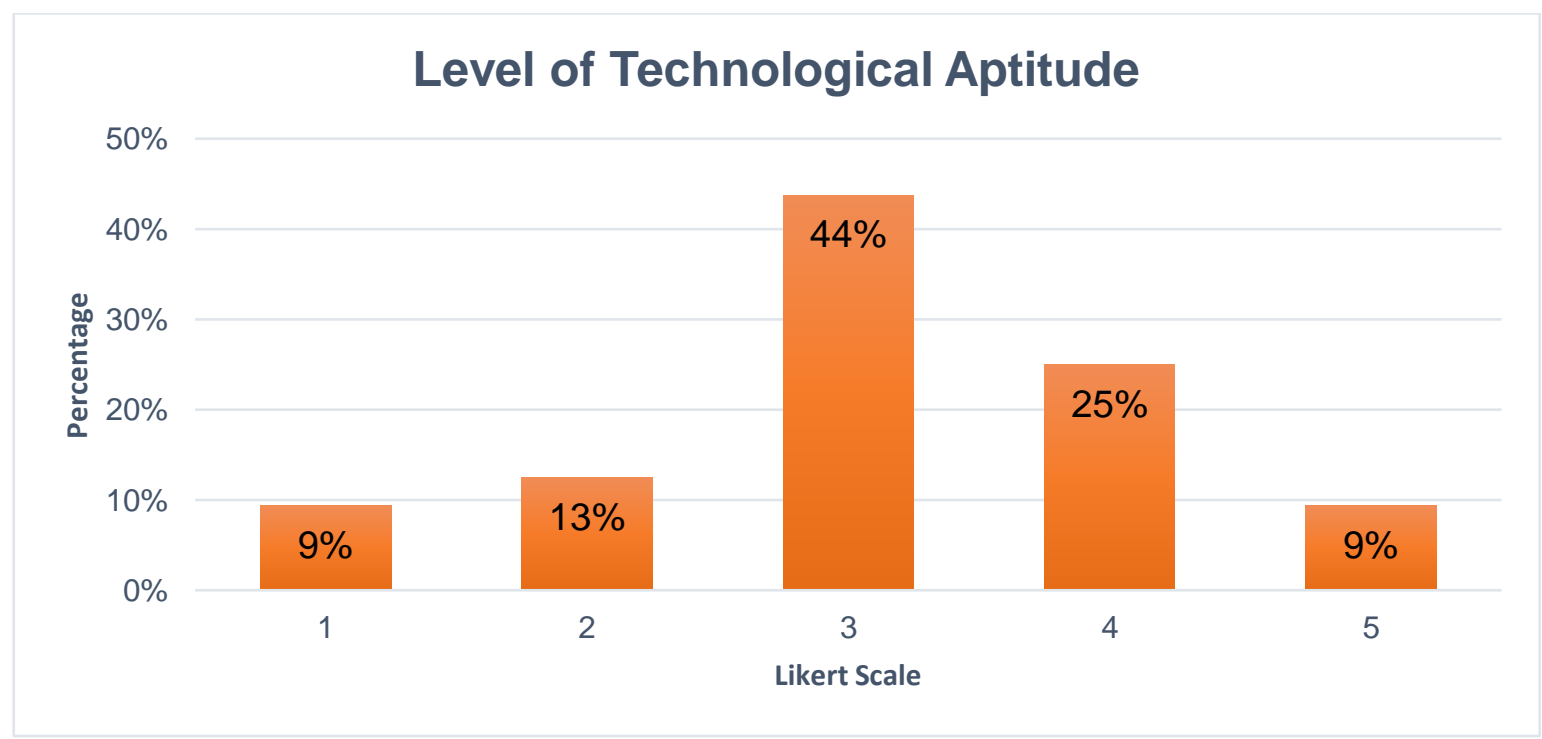

Fig. 19 Graph for the level of technological aptitude (Liker scale: 1-5) 
2. A smart home is a home that is equipped with technology to remotely control and automate household systems like lighting, thermostats, entertainment systems, and other connected appliances. Do you own any of these devices?

\section{Do you own any smart home devices?}

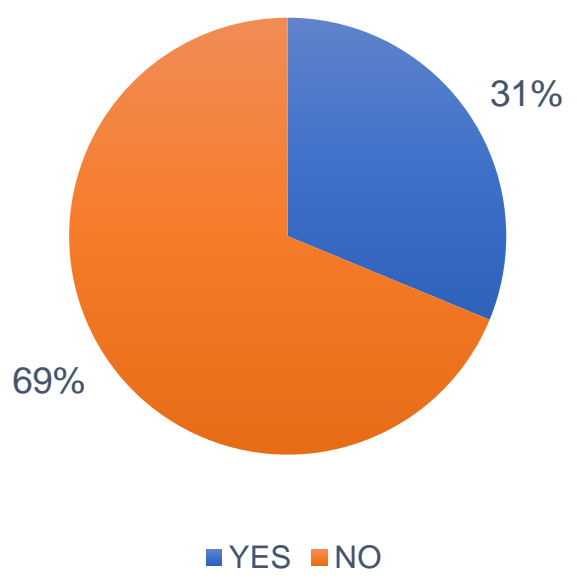

Fig. 20 Graph showing distribution of participants who own smart home devices

3. If yes, which devices?

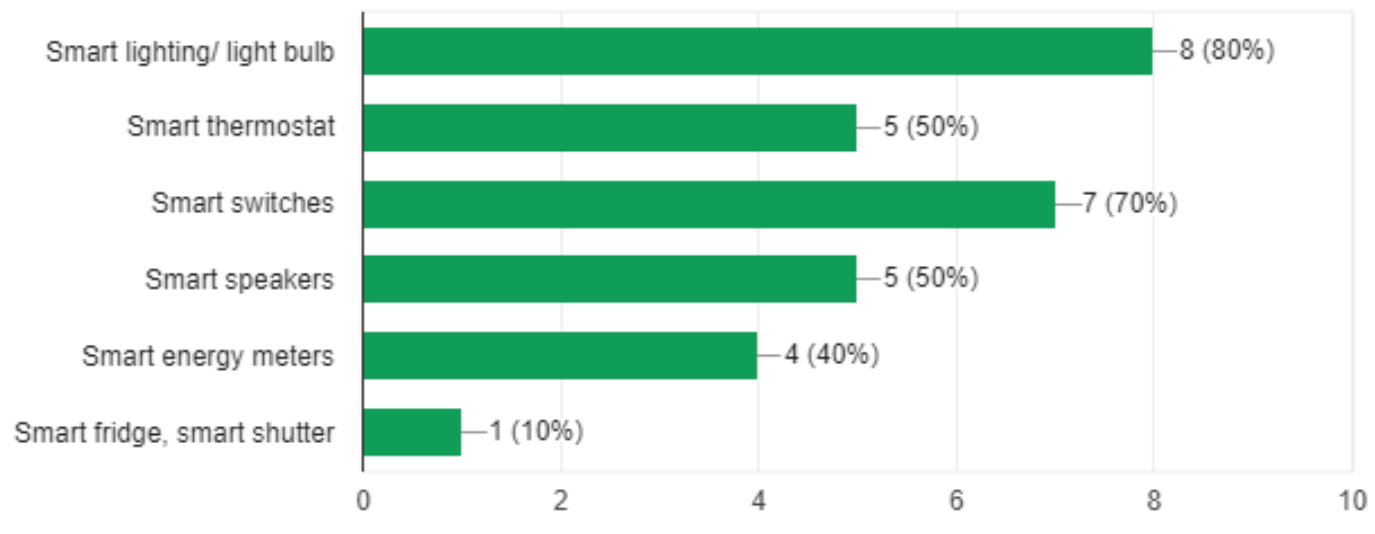

Fig. 21 Graph of smart home devices some participants own 
4. If no, are you interested in smart home devices for your home?

\section{Are you interested in smart home devices for your home?}

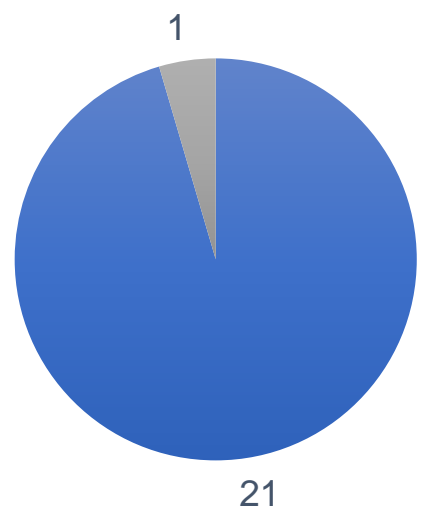

-YES $\square$ NO

Fig. 22 Graph showing the distribution of participants who does not own any smart home devices but are interested to have them at home 


\subsection{Socio-Technical Evaluations}

As previously mentioned, Likert-type scale or rating scale is a psychometric tool to gauge someone's level of agreement or disagreement on a symmetric agree-disagree scale. A Likert scale is the sum of response on several Likert items - series of statements. This range captures the intensity of their feeling for a given item. The three sets of Likert scales for each chosen socio-technical aspect will be presented below and conclusions will be drawn to further discuss the result of the study.

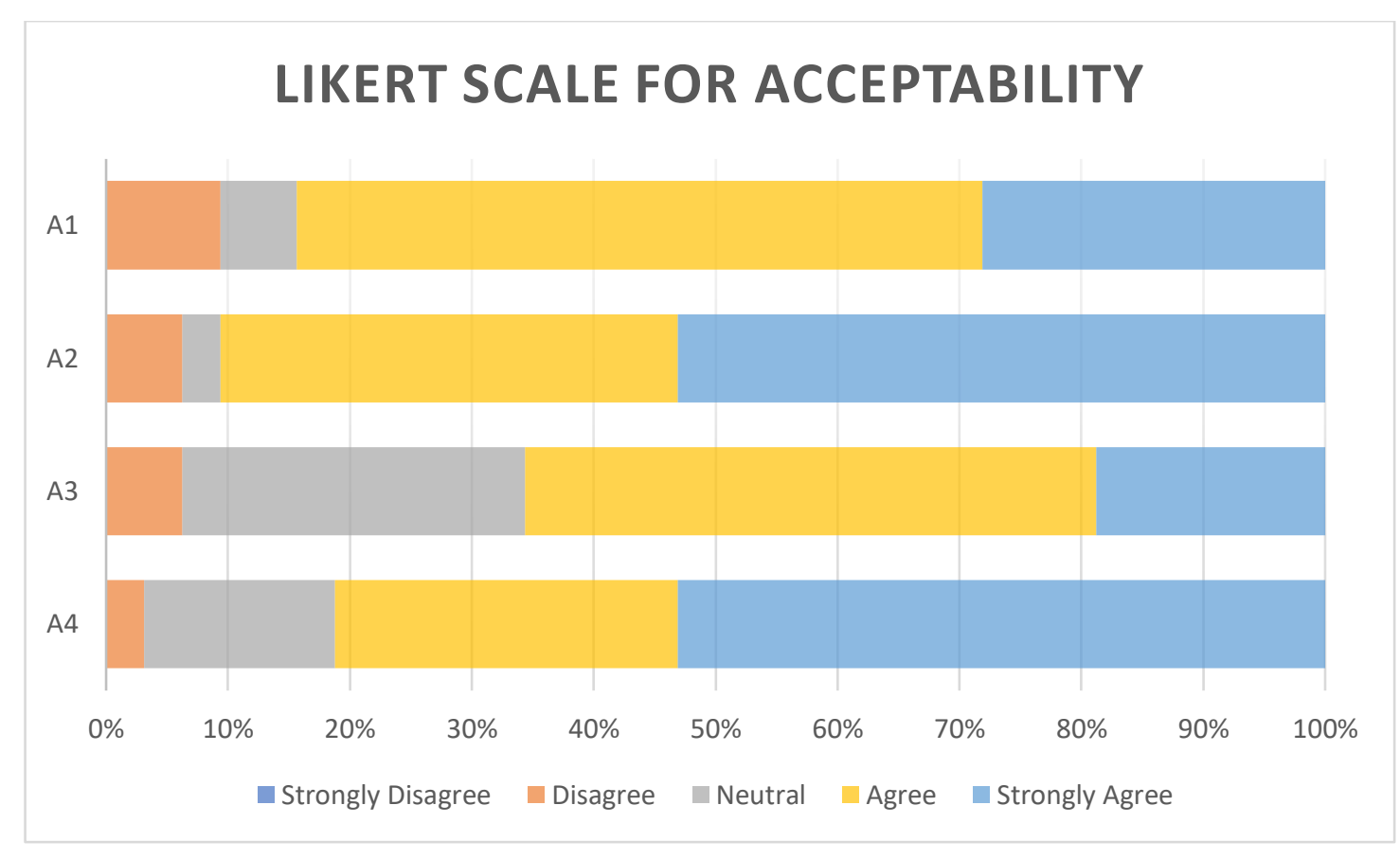

Fig. 23 Likert Scale for Acceptability 
Table 9 Statistical Table for Acceptability

\begin{tabular}{lrrrr}
\hline & A1 & A2 & A3 & A4 \\
\hline MEAN & 4.03125 & 4.375 & 3.78125 & 4.3125 \\
STANDARD ERROR & 0.152164325 & 0.147218841 & 0.147111811 & 0.151853 \\
MEDIAN & 4 & 5 & 4 & 5 \\
MODE & 4 & 5 & 4 & 5 \\
STANDARD DEVIATION & 0.860771409 & 0.832795525 & 0.832190076 & 0.859013 \\
SAMPLE VARIANCE & 0.740927419 & 0.693548387 & 0.692540323 & 0.737903 \\
KURTOSIS & 1.05545 & 2.387452 & -0.31288 & 0.088865 \\
SKEWNESS & -1.033403 & -1.541459 & -0.273213 & -1 \\
RANGE & 3 & 3 & 3 & 3 \\
MINIMUM & 2 & 2 & 2 & 2 \\
MAXIMUM & 5 & 5 & 5 & 5 \\
SUM & 129 & 140 & 121 & 138 \\
COUNT & 32 & 32 & 32 & 32 \\
CONFIDENCE LEVEL(95.0\%) & 0.310341187 & 0.300254805 & 0.300036518 & 0.309707 \\
\hline
\end{tabular}

For Acceptability, Likert item A2 (Perceived Ease-of-Use) has the highest mean of 4.37/5.0. A standard deviation closer to 0 indicates that the data points tend to be very close to the mean or expected value of the set. This Likert set has a standard deviation value that plays around $0.83-0.86$ for the following four Likert items. The items seem to be as equally distant to the mean which suggests a well distributed sample population. Thus, opinions regarding the socio-technical aspect of Acceptability can be seen as both diverse yet keeping it on a high positive note simultaneously. 


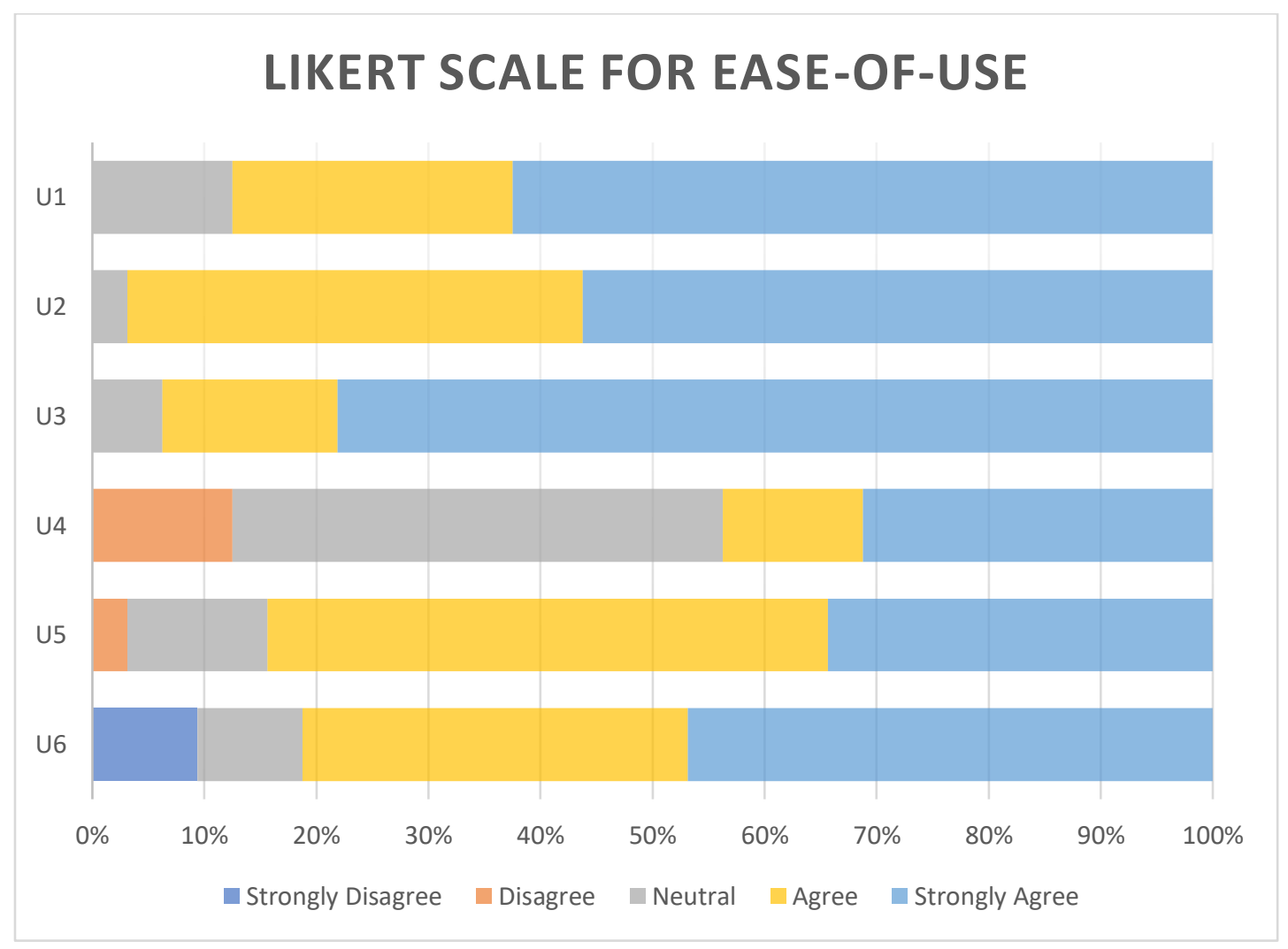

Fig. 24 Likert Scale for Ease-of-use

Table 10 Statistical Table for Ease-of-use

\begin{tabular}{lrrrrrr}
\hline & U1 & U2 & U3 & U4 & U5 & U6 \\
\hline MEAN & 4.5 & 4.53125 & 4.71875 & 3.625 & 4.15625 & 4.09375 \\
STANDARD ERROR & 0.127000 & 0.100245 & 0.102728 & 0.189 & 0.13552 & 0.212319 \\
MEDIAN & 5 & 5 & 5 & 3 & 4 & 4 \\
MODE & 5 & 5 & 5 & 3 & 4 & 5 \\
STANDARD DEVIATION & 0.718421 & 0.567073 & 0.581120 & 1.070 & 0.76661 & 1.201058 \\
SAMPLE VARIANCE & 0.516129 & 0.321572 & 0.337701 & 1.145 & 0.58770 & 1.442540 \\
KURTOSIS & -0.080172 & -0.51101 & 3.190408 & -1.347 & 0.58031 & 2.128555 \\
SKEWNESS & -1.113552 & -0.695425 & -2.008470 & 0.157 & -0.7379 & -1.620630 \\
RANGE & 2 & 2 & 2 & 3 & 3 & 4 \\
MINIMUM & 3 & 3 & 3 & 2 & 2 & 1 \\
MAXIMUM & 5 & 5 & 5 & 5 & 5 & 5 \\
SUM & 144 & 145 & 151 & 116 & 133 & 131 \\
COUNT & 32 & 32 & 32 & 32 & 32 & 32 \\
CONFIDENCE & & & & & & \\
LEVEL(95.0\%) & 0.259018 & 0.204451 & 0.209516 & 0.385 & 0.27639 & 0.433027 \\
\hline
\end{tabular}




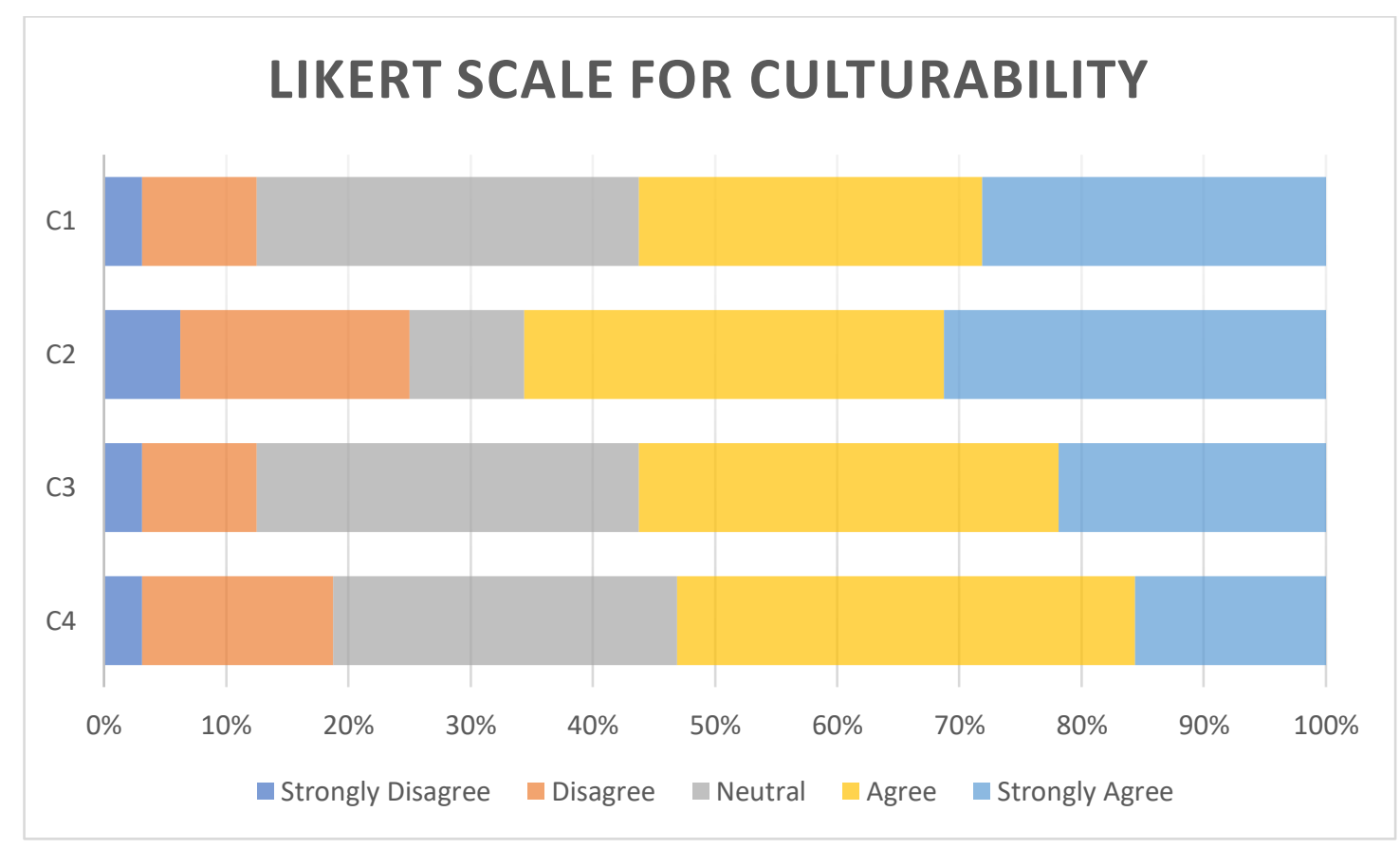

Fig. 25 Likert Scale for Culturability

Table 11 Statistical Table for Culturability

\begin{tabular}{lrrrr}
\hline & C1 & C2 & C3 & C4 \\
\hline MEAN & 3.6875 & 3.65625 & 3.625 & 3.46875 \\
STANDARD ERROR & 0.192801398 & 0.227226329 & 0.183766595 & 0.185048 \\
MEDIAN & 4 & 4 & 4 & 4 \\
MODE & 3 & 4 & 4 & 4 \\
STANDARD DEVIATION & 1.090649407 & 1.285386223 & 1.039540842 & 1.046788 \\
SAMPLE VARIANCE & 1.189516129 & 1.652217742 & 1.080645161 & 1.095766 \\
KURTOSIS & -0.3937772 & -0.760277 & -0.123065 & -0.40198 \\
SKEWNESS & -0.436375 & -0.66234 & -0.447958 & -0.36191 \\
RANGE & 4 & 4 & 4 & 4 \\
MINIMUM & 1 & 1 & 1 & 1 \\
MAXIMUM & 5 & 5 & 5 & 5 \\
SUM & 118 & 117 & 116 & 111 \\
COUNT & 32 & 32 & 32 & 32 \\
CONFIDENCE LEVEL(95.0\%) & 0.393221044 & 0.463431153 & 0.374794441 & 0.377407 \\
\hline
\end{tabular}


Table 12 Statistical Table for Summary/ Debriefing Questions

\begin{tabular}{lrrr}
\hline & S1 & S3 & S2 \\
\hline MEAN & 4.15625 & 3.53125 & 3.625 \\
STANDARD ERROR & 0.16257365 & 0.19041749 & 0.209405841 \\
MEDIAN & 4 & 4 & 4 \\
MODE & 5 & 4 & 5 \\
STANDARD DEVIATION & 0.91965544 & 1.077163988 & 1.184578324 \\
SAMPLE VARIANCE & 0.845766129 & 1.160282258 & 1.403225806 \\
KURTOSIS & -0.06936421 & -0.472869708 & -0.935503711 \\
SKEWNESS & -0.858745208 & -0.416352188 & -0.318266413 \\
RANGE & 3 & 4 & 4 \\
MINIMUM & 2 & 1 & 1 \\
MAXIMUM & 5 & 5 & 5 \\
SUM & 133 & 113 & 116 \\
COUNT & 32 & 32 & 32 \\
CONFIDENCE LEVEL(95.0\%) & 0.331571144 & 0.388359032 & 0.427086029 \\
\hline
\end{tabular}

For Ease-of-use, Likert item U3 (Efficiency) got the highest mean of 4.72/5.0. It is rather interesting to investigate Likert item U4 (Error) which got the lowest mean of 3.62/5.0 from the Likert scale. It also has both the highest standard deviation of 1.07 and highest variance of 1.145 in that specific set. Looking into Culturability, Likert item C1 (Intuitiveness) garnered the highest mean of 3.69/5.0. Among the other Likert Scales, this set shows variance values from 1.081 to 1.190 . A high variance value indicates that the data point is very spread out both from the mean, and from one another. This will be further investigated in the following sections regarding the use of the ANOVA technique.

\subsection{Cronbach's Alpha}

As suggested by Rubin, et.al [48], inferential statistical techniques can be used to further analyze datasets such as Likert items. These techniques can be used to prove cause-andeffect relationship, and to either confirm or reject a given hypothesis, among others. One method that will be used for this study is the measure of the Cronbach's Alpha value. Otherwise known as the Coefficient Alpha, the Cronbach's Alpha is a measure of internal 
consistency [48]. For sets of more than ten items, an Alpha value greater than 0.70 displays a highly consistent and well sorted out value.

Table 13 Statistical Table of Participants (Cronbach's Alpha)

\begin{tabular}{lrrrr}
\hline SUMMARY & Count & Sum & Average & Variance \\
\hline Participant 1 & 17 & 85 & 5 & 0 \\
Participant 2 & 17 & 62 & 3.647059 & 1.367647 \\
Participant 3 & 17 & 71 & 4.176471 & 0.529412 \\
Participant 4 & 17 & 57 & 3.352941 & 1.492647 \\
Participant 5 & 17 & 68 & 4 & 0.875 \\
Participant 6 & 17 & 72 & 4.235294 & 0.816176 \\
Participant 7 & 17 & 73 & 4.294118 & 0.845588 \\
Participant 8 & 17 & 72 & 4.235294 & 0.441176 \\
Participant 9 & 17 & 61 & 3.588235 & 1.507353 \\
Participant 10 & 17 & 52 & 3.058824 & 0.558824 \\
Participant 11 & 17 & 67 & 3.941176 & 0.183824 \\
Participant 12 & 17 & 48 & 2.823529 & 0.904412 \\
Participant 13 & 17 & 67 & 3.941176 & 1.433824 \\
Participant 14 & 17 & 80 & 4.705882 & 0.345588 \\
Participant 15 & 17 & 66 & 3.882353 & 0.985294 \\
Participant 16 & 17 & 70 & 4.117647 & 0.610294 \\
Participant 17 & 17 & 75 & 4.411765 & 0.382353 \\
Participant 18 & 17 & 72 & 4.235294 & 1.191176 \\
Participant 19 & 17 & 73 & 4.294118 & 0.720588 \\
Participant 20 & 17 & 66 & 3.882353 & 1.110294 \\
Participant 21 & 17 & 73 & 4.294118 & 0.720588 \\
Participant 22 & 17 & 73 & 4.294118 & 0.470588 \\
Participant 23 & 17 & 73 & 4.294118 & 1.470588 \\
Participant 24 & 17 & 68 & 4 & 1.125 \\
Participant 25 & 17 & 81 & 4.764706 & 0.441176 \\
Participant 26 & 17 & 68 & 4 & 1 \\
Participant 27 & 17 & 61 & 3.588235 & 0.757353 \\
Participant 28 & 17 & 44 & 2.588235 & 0.757353 \\
Participant 29 & 17 & 69 & 4.058824 & 1.183824 \\
Participant 30 & 17 & 77 & 4.529412 & 0.389706 \\
Participant 31 & 17 & 62 & 3.647059 & 0.617647 \\
Participant 32 & 17 & 66 & 3.882353 & 1.110294 \\
\hline & & & & \\
\hline
\end{tabular}


Table 14 Statistical Table for Questions (Cronbach's Alpha)

\begin{tabular}{lrrrr}
\hline SUMMARY & Count & Sum & Average & Variance \\
\hline Question 1 & 32 & 118 & 3.6875 & 1.189516 \\
Question 2 & 32 & 129 & 4.03125 & 0.740927 \\
Question 3 & 32 & 140 & 4.375 & 0.693548 \\
Question 4 & 32 & 121 & 3.78125 & 0.69254 \\
Question 5 & 32 & 138 & 4.3125 & 0.737903 \\
Question 6 & 32 & 144 & 4.5 & 0.516129 \\
Question 7 & 32 & 131 & 4.09375 & 1.44254 \\
Question 8 & 32 & 145 & 4.53125 & 0.321573 \\
Question 9 & 32 & 151 & 4.71875 & 0.337702 \\
Question 10 & 32 & 116 & 3.625 & 1.145161 \\
Question 11 & 32 & 133 & 4.15625 & 0.587702 \\
Question 12 & 32 & 116 & 3.625 & 1.080645 \\
Question 13 & 32 & 117 & 3.65625 & 1.652218 \\
Question 14 & 32 & 111 & 3.46875 & 1.095766 \\
Question 15 & 32 & 133 & 4.15625 & 0.845766 \\
Question 16 & 32 & 113 & 3.53125 & 1.160282 \\
Question 17 & 32 & 116 & 3.625 & 1.403226 \\
\hline
\end{tabular}

Table 15 Statistical Table Summry for Cronbach's Alpha

\begin{tabular}{lcccccc}
\hline \multicolumn{1}{c}{ Source of Variation } & SS & $\boldsymbol{d f}$ & $\boldsymbol{M S}$ & $\boldsymbol{F}$ & P-value & $\boldsymbol{F}$ crit \\
\hline Participants (Rows) & 144.4412 & 31 & 4.659393 & 6.787324 & $5.47 \mathrm{E}-23$ & 1.474467 \\
Questions (Columns) & 81.03309 & 16 & 5.064568 & 7.377541 & $1.43 \mathrm{E}-15$ & 1.663927 \\
Error & 340.4963 & 496 & 0.686485 & & & \\
& & & & & & \\
Total & 565.9706 & 543 & & & & \\
\hline
\end{tabular}

Using the variables presented in Table 15, the Cronbach's Alpha value can be computed as:

$$
\alpha=1-\frac{M S_{\text {Error }}}{M S_{\text {Rows }}}
$$

where $\mathrm{MS}_{\mathrm{ERROR}}$ is the mean-square value for the error which is the difference of the rows and sum, while $\mathrm{MS}_{\mathrm{ROwS}}$ is the mean-square value of the rows side. With that, we compute a Cronbach's Alpha value of 0.85267 , which is considered a good alpha value for internal consistency. 


\subsection{Analysis of Variance}

In addition to the technique mentioned in the previous section, the Analysis of Variance (ANOVA) is also a very useful inferential statistical technique that can be used in Likert scales and datasets such as these. The Analysis of Variance, or more commonly referred to as ANOVA, can be used to analyze the difference between and among group means in a sample. ANOVA provides a statistical test of whether the means of several groups are equal, and therefore generalizes the t-test.

First, the both $\mathrm{H}_{0}$ and $\mathrm{H}_{1}$ hypotheses are set, where $\mathrm{H}_{0}$, or the null hypothesis, is the hypothesis that follows the status quo, or the norm set by the context of the study, while $\mathrm{H}_{1}$ is the opposite or the hypothesis which deviate or go against the null hypothesis. For this ANOVA study, the following hypotheses are set as:

$\mathrm{H}_{0}$ : "Cultural background does not relate or affect opinion regarding gesture interactions for smart homes."

$\mathrm{H}_{1}$ : "Cultural background relates or affects opinion regarding gesture interactions for smart homes."

To either confirm or deny the null-hypothesis, an analysis of variance (ANOVA) can be performed. For this specific ANOVA case, three sets of data from seven participants each coming from 3 different counties (Spain, France, and Germany) were collected. The F-value is then computed using the following formula:

$$
F=\frac{\text { variance between treatments }}{\text { variance within treatments }}
$$

Thus,

$$
F=\frac{M S_{\text {Treatment }}}{M S_{\text {Error }}}
$$


where $\mathrm{MS}_{\text {Treatment }}$ is the mean-square of the treatments or the variance between treatments, and $\mathrm{MS}_{\mathrm{Error}}$ is the mean-square of the error variable or the variance within treatments. This formula can also be expressed as:

$$
F=\frac{S S_{\text {Treatment }} /(I-1)}{S S_{\text {Error }} /\left(n_{T}-1\right)}
$$

where $\mathrm{I}$ is the number of treatments and $\mathrm{n}_{\mathrm{T}}$ is the total number of cases to the F-distribution with (I-1), and ( $\left.\mathrm{n}_{\mathrm{T}}-1\right)$ degrees of freedom or DOE.

Table 16 Statistical Table Summary for ANOVA

\begin{tabular}{ccccc}
\hline Groups & Count & Sum & Average & Variance \\
\hline Group 1 & 7 & 27 & 3.857143 & 0.809524 \\
Group 2 & 7 & 23 & 3.285714 & 1.571429 \\
Group 3 & 7 & 31 & 4.428571 & 0.285714 \\
\hline
\end{tabular}

Table 17 ANOVA: Single Factor Values

\begin{tabular}{lrrrrrc}
\hline Source of Variation & \multicolumn{1}{c}{ SS } & df & MS & F & P-value & F crit \\
\hline Between Groups & 4.571429 & 2 & 2.285714 & 2.571429 & 0.10416 & 3.554557 \\
Within Groups & 16 & 18 & 0.888889 & & & \\
& & & & & & \\
Total & 20.57143 & 20 & & & & \\
\hline
\end{tabular}

From the Table 17 above, the computed F-value is at 2.571429 given the F-critical of 3.554557. The critical value of $\mathrm{F}$ is a function of the degrees of freedom of the numerator and the denominator and the significance level $(\alpha)$. If F-value $\geq F$-critical, the null hypothesis is rejected. The F-values for other possible sets were also compared to the F-critical value based on the F-distribution curve table of values, and no Likert scale had a F-value greater than or equal to any given set F-critical. Thus, in this case, the null hypothesis is not categorically confirmed nor rejected. 


\section{DISCUSSIONS}

This chapter will be divided into three sections: (a) Design Science Guidelines to look back at the framework of the Design Science Research as presented in Chapter 2; (b) Gap Analysis and Novel Contribution to address the relevant research questions (RQs); and (c) Sustainability Claim using Sustainability Analysis Pentagon.

\subsection{Design Science Guidelines}

Going back to the Design Science Research [6][50][8] methodology framework, each guideline will be reviewed to see if the process was properly and diligently followed.

Design Science Guidelines:

1. There has to be an artifact.

The artifact in this face is the integration of the gesture dictionary to a gesture recognition technology in controlling smart home devices.

2. The problem should be relevant.

The relevance of this study was reiterated in the introduction and in the review of related works. Home- and building automation technologies have been commercially available for some time now however, there has been struggles for the majority to fully adapt it in their homes brought by usability and interoperability issues.

\section{Effectively evaluate design.}

To do so, the socio-technical aspects served as the corner stones to measure the level of naturalness and intuitiveness of gesture interaction. Concepts such as descriptive analysis, and inferential statistical techniques helped to make sense out of the Likert items and eventually each set of Likert scales.

4. Two types of research contributions - to the field and to the knowledge-base.

The research contributes to the field of Human-Computer Interaction (HCI) through the better understanding of the relationship of gesture interactions and home automation 
systems. In addition, it also investigates on socio-technical aspects in contrast to heavily technical aspects previously studied such as the efficiency of gesture recognition approaches and algorithms, and reliability of motion capture technologies as presented in the related works.

5. It has to have rigor - draw from knowledge base appropriately in terms of foundational theories and experimental design.

With the help of the Design Science Research methodology framework, rigor was strongly identified in this research. The framework served as helpful tool to apply foundational theories such as the statistical techniques (descriptive analysis, Cronbach's Alpha, and ANOVA) and the experimental design such as those in the field of HCI (perceptual technologies, gesture styles, and socio-technical aspects).

6. Design is a search process - characterize the problem or opportunity in a search space, then find the "satisficing design" (Herbert Simon).

Brought by the research questions, the problem was explored as a search process of finding minimum requirements to satisfy necessary to achieve the research objectives. This opportunity was also pursued given the particular action plans.

7. Communicate results appropriately.

Lastly, this research was successfully presented in the $4^{\text {th }}$ Annual PERCCOM Summer School which was held Finland this year. In addition, papers written on the topic were accepted in two international conferences - the SEEDS Conference 2018 in Dublin, Ireland, and the Sensors \& Actuators Conference 2018 in Stockholm, Sweden. 


\subsection{Gap Analysis and Novel Contribution}

During the course of this study, the following were gaps were identified. The novel contributions brought by this thesis bridge these gaps. These would also serve as the answers for the research questions presented in Chapter 1 Introduction.

Identifying the Gaps:

1. While several studies have showed the potential of motion capture sensors outside of gaming and entertainment, in areas such as tele-rehabilitation, aid for the elderly and people-with-disabilities, and digital interactions, this study investigates on the use of the Kinect and LEAP Motion Control to interact with home automation systems to attain a higher uptake for smart home technologies towards promoting sustainability.

2. While several studies have investigated on models and methods in meaningful gestures on screens, gloves, pens, and other non-perceptual technologies that require physical contact, this study focuses on defining a set of "in-air" gestures with attention to making a natural and intuitive way of interacting with home automation systems.

3. While several studies have looked into reliability, accuracy, and efficiency in using the Kinect and LEAP Motion for gesture recognition, this study will conduct a usability testing of these technologies to attain a level of acceptability, ease of use, and gesture anthropology to better understand the relation of gesture control and home automation systems. 


\subsection{Sustainability Claim}

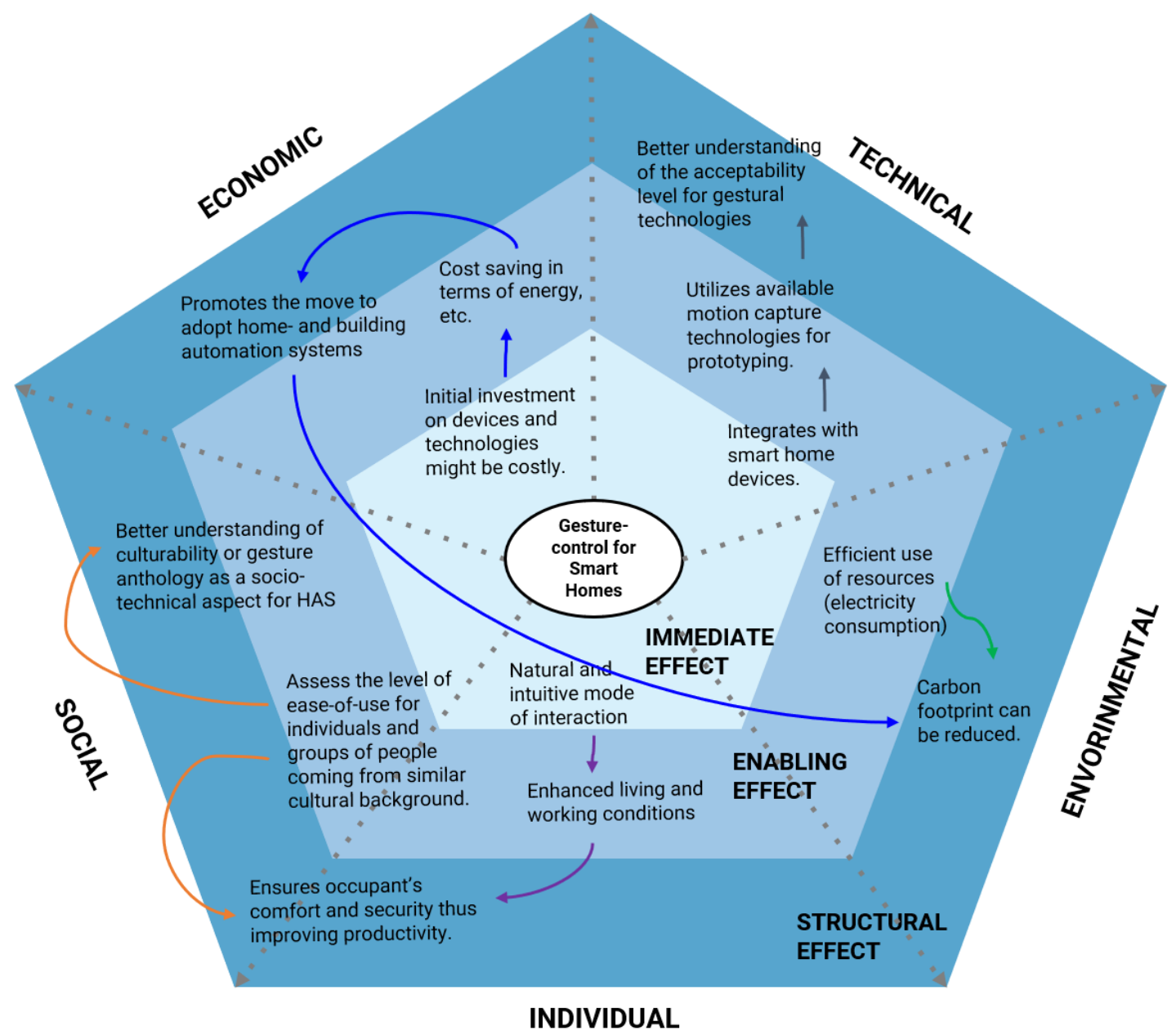

Table 18 Sustainability Analysis Pentagon

Based on a recent study by Becker, et.al [49] on classifying the different requirements to further analyze sustainability in software engineering, and ICT systems, the sustainability analysis pentagon was derived. Five interrelated dimensions are investigated: (a) individual dimension, (b) social dimension, (c) economic dimension, (d) technical dimension, and (e) environmental dimension, across three different effective layers, namely immediate, enabling and structural. 
In the context of this study, Gesture-Control for Smart Homes was placed in the middle of the sustainability analysis pentagon. The different dimensions will then be explored beginning with the environmental dimension. Efficient use of resources such as electricity consumption is considered as the enabling effect, thus eventually reducing the total carbon footprint which serves as the structural effect. For the technical dimension, the research integrates smart home devices as an immediate effect, then the enabling effect is the use of available motion capture technologies for prototyping, which brings about a better understanding of acceptability level for gestural technologies for home automation systems. Next, the individual dimension corresponds to a more natural and intuitive mode of interaction for its immediate effect, then enhanced living and working conditions serves as its enabling effect. Having an ensured occupant's comfort and security, towards an overall improved productivity is the structural effect shared with the social dimension. Other than that, there is also the better understanding of culturability or gesture anthropology as a sociotechnical aspect for HAS, brought by assessing the level of ease-of-se for individuals and groups of people coming from similar cultural background as the enabling effect for the social dimension. Lastly, for the economic dimension, initial investment on devices and technology serves as the immediate effect. The enabling effect comes in the cost saving in terms of energy and other resources, leading to promoting the move to adoption of homeand building automation systems as the structural effect. This points to the overall reduction of carbon footprint in the environmental dimension. 


\section{CONCLUSION}

The study implemented and tested a proposed proof-of-concept using prospective motion capture sensors in the context of home automation. A set of gestures were defined as meaning actions to interact with smart home devices. A socio-technical study was conducted to measure a level of acceptance, ease-of-use, and culturability. A positive feedback from the heuristics suggests that the gesture interactions for HAS are indeed categorically natural and intuitive. The study then responds to the challenge of improving the up-take of HAS thus maximizing its potentials towards designing and maintaining buildings of the future that are both user-centric and resource efficient to reduce our overall carbon footprint.

As recommendations for future researchers that would pursue a topic similar to this thesis, test the technology to a bigger range of respondents with a well-defined population and sample, perhaps smart home early adopters and HAS enthusiast who already have experience with the technology. In addition, define more gesture vocabularies with available smart home devices. This study was restricted with readily available smart home devices to control. Also, the issue in integrating HAS in a common server affected the range of defined vocabularies, thus improving the interoperability would greatly enhance the knowledgebase. Lastly, consider integrating other multimedia natural user interfaces (NUI) such as voice assistant, multi-touch surfaces, or even virtual reality/ augmented reality when interacting with home automation systems. 


\section{REFERENCES}

[1] J. Porras, A. Seffah, E. Rondeau, K. Andersson, and K. Alexandra, "PERCCOM: A Master Program in Pervasive Computing and COMmunications for Sustainable Development," no. APRIL, 2016.

[2] "Energy trends - Statistics Explained," 2017. [Online]. Available: http://ec.europa.eu/eurostat/statistics-explained/index.php?title=Energy_trends. [Accessed: 21-May-2018].

[3] "Buildings - European Commission." [Online]. Available: https://ec.europa.eu/energy/en/topics/energy-efficiency/buildings. [Accessed: 21May-2018].

[4] GeSI, “\#SMARTer2030,” 2015. [Online]. Available: http://smarter2030.gesi.org/downloads/Full_report.pdf. [Accessed: 21-May-2018].

[5] O. Droegehorn, M. Pittumbur, and J. Porras, "Front-End Development for Home Automation Systems: A design approach using JavaScript Frameworks," SEEDS Conf., 2017.

[6] A. R. Hevner, "Scandinavian Journal of Information Systems A Three Cycle View of Design Science Research A Three Cycle View of Design Science Research," Scand. J. Inf. Syst. (C) Scand. J. Inf. Syst., vol. 19, no. 192, pp. 87-92, 2007.

[7] G. Tran, “GreenBe - A System To Capture and Visualize User's Energy -Related Activities For Facilitating Greener Energy Behavior,” SEEDS Conf., 2017.

[8] A. Hevner and S. Chatterjee, "Design Research in Information Systems," vol. 22, pp. 9-23, 2010.

[9] P. David, N. Collete, and G. Magdalen, "Review of the current status of research on smart homes and other domestic assistive technologies in support of the TAHI trials Review of the current status of research on ' Smart Homes' and other domestic assistive technologies in support of TAHI trials," Loughbrgh. Univ., 2002.

[10] J. F. Malcolm, “The Implications of Smart Home Technologies,” S. Peace, C. Holl. Incl. Hous. Ageing, pp. 101-124, 2014.

[11] C. Martinez, "Remote control-based home automation usability evaluation," SEEDS Conf., 2017. 
[12] L. Garber, "Gestural Technology: Moving Interfaces in a New Direction.," Computer (Long. Beach. Calif)., vol. 46, no. 10, pp. 22-25, 2013.

[13] M. Karam and m. c. Schraefel, “A Taxonomy of Gestures in Human Computer Interactions," Tech. Report, Eletronics Comput. Sci., pp. 1-45, 2005.

[14] A. C. De Carvalho Correia, L. C. De Miranda, and H. Hornung, "Gesture-based interaction in domotic environments: State of the art and HCI framework inspired by the diversity," Lect. Notes Comput. Sci. (including Subser. Lect. Notes Artif. Intell. Lect. Notes Bioinformatics), vol. 8118 LNCS, no. PART 2, pp. 300-317, 2013.

[15] J. Han, L. Shao, D. Xu, and J. Shotton, "Enhanced computer vision with Microsoft Kinect sensor: A review," IEEE Trans. Cybern., vol. 43, no. 5, pp. 1318-1334, 2013 .

[16] Z. Zhang, "Microsoft kinect sensor and its effect," IEEE Multimed., vol. 19, no. 2, pp. 4-10, 2012.

[17] G. Panger, "Kinect in the kitchen: testing depth camera interactions in practical home environments," Proc. CHI 2012 Ext. Abstr., pp. 1985-1990, 2012.

[18] H.-J. Kim, K.-H. Jeong, S.-K. Kim, and T.-D. Han, “Ambient Wall: Smart Wall Display Interface Which Can Be Controlled By Simple Gesture for Smart Home," SIGGRAPH Asia 2011 Sketches - SA '11, p. Article 1, 2011.

[19] J. H. Oh, Y. Jung, Y. Cho, C. Hahm, H. Sin, and J. Lee, "Hands-up: motion recognition using kinect and a ceiling to improve the convenience of human life," Proc. CHI 2012 Ext. Abstr., pp. 1655-1660, 2012.

[20] Y. You, T. Tang, and Y. Wang, "When arduino meets Kinect: An intelligent ambient home entertainment environment," Proc. - 2014 6th Int. Conf. Intell. Human-Machine Syst. Cybern. IHMSC 2014, vol. 2, pp. 150-153, 2014.

[21] H.-Y. Lin, Y.-L. Hsueh, and W.-N. Lie, “Abnormal Event Detection Using Microsoft Kinect in a Smart Home," Proc. - 2016 Int. Comput. Symp. ICS 2016, pp. 285-289, 2017.

[22] W. Zhao and R. Lun, "A Kinect-based system for promoting healthier living at home," 2016 IEEE Int. Conf. Syst. Man, Cybern. SMC 2016 - Conf. Proc., pp. 258 263, 2017.

[23] G. Blumrosen, Y. Miron, M. Plotnik, and N. Intrator, "Towards a Real-Time Kinect Signature Based Human Activity Assessment at Home," Wearable Implant. Body 
Sens. Networks (BSN), 2015 IEEE 12th Int. Conf., 2015.

[24] A. Iqbal, S. Asrafuzzaman, M. Arifin, and S. K. A. Hossain, "Smart Home Appliance Control System for Physically Disabled People Using Kinect and X10,” pp. 891-896, 2016.

[25] J. A. Piedra-Fernandez, J. J. Ojeda-Castelo, C. Bernal-Bravo, and L. IribarneMartinez, "Sign Communication for People with Disabilities Using Kinect Technology at Home," 2016 8th Int. Conf. Games Virtual Worlds Serious Appl., pp. $1-2,2016$.

[26] Z. Zhang, "Robust Hand Gesture Recognition Based on Finger- Earth Mover's Distance with a Commodity Depth Camera," Hand, pp. 1093-1096, 2011.

[27] Z. Ren, J. Meng, J. Yuan, and Z. Zhang, "Robust Hand Gesture Recognition with Kinect Sensor," Proc. 19th ACM Int. Conf. Multimed., pp. 759-760, 2011.

[28] H. Cook, Q. V. Nguyen, S. Simoff, T. Trescak, and D. Preston, “A Close-Range Gesture Interaction with Kinect,” 2015 Big Data Vis. Anal. BDVA 2015, 2015.

[29] D. Wu, F. Zhu, L. Shao, and H. Zhang, "One shot learning gesture recognition with Kinect sensor," Proc. 20th ACM Int. Conf. Multimed. - MM '12, p. 1303, 2012.

[30] M. C. B. Seixas, J. C. S. Cardoso, and M. T. G. Dias, “The Leap Motion Movement for 2D Pointing Tasks - Characterisation and Comparison to Other Devices," Proc. 5th Int. Conf. Pervasive Embed. Comput. Commun. Syst., pp. 15-24, 2015.

[31] A. F. Cavalcanti, F. B. S. de Medeiros, and R. R. Dantas, "Evaluate Leap Motion Control for Multiple Hand Posture Recognition,” 2017 19th Symp. Virtual Augment. Real., pp. 341-344, 2017.

[32] P. D. S. H. Gunawardane and N. T. Medagedara, "Comparison of Hand Gesture inputs of Leap Motion Controller \& Data Glove in to a Soft Finger," pp. 62-68, 2017.

[33] J. Guna, G. Jakus, M. Pogačnik, S. Tomažič, and J. Sodnik, “An analysis of the precision and reliability of the leap motion sensor and its suitability for static and dynamic tracking," Sensors (Switzerland), vol. 14, no. 2, pp. 3702-3720, 2014.

[34] C. Siegl, J. Süßmuth, F. Bauer, and M. Stamminger, "Evaluating the usability of recent consumer-grade 3D input devices," GRAPP 2014 - Proc. 9th Int. Conf. Comput. Graph. Theory Appl., pp. 417-423, 2014.

[35] S. Ameur, A. Ben Khalifa, and M. S. Bouhlel, “A comprehensive leap motion 
database for hand gesture recognition," 2016 7th Int. Conf. Sci. Electron. Technol. Inf. Telecommun. SETIT 2016, no. July 2013, pp. 514-519, 2017.

[36] R. B. Mapari and G. Kharat, "Real time human pose recognition using leap motion sensor," 2015 IEEE Int. Conf. Res. Comput. Intell. Commun. Networks, pp. 323 $328,2015$.

[37] P. Kumar, R. Saini, S. K. Behera, D. P. Dogra, and P. P. Roy, "Real-time recognition of sign language gestures and air-writing using leap motion," Proc. 15th IAPR Int. Conf. Mach. Vis. Appl. MVA 2017, vol. 1, pp. 157-160, 2017.

[38] G. Ponraj and H. Ren, "Sensor Fusion of Leap Motion Controller and Flex Sensors Using Kalman Filter for Human Finger Tracking,” vol. 18, no. 5, pp. 2042-2049, 2018.

[39] I. G. A. Dharmayansa, "Exploration of Prayer Tools in 3D Virtual Museum Using Leap Motion For Hand Motion Sensor,” 2017 TRON Symp., pp. 1-8, 2017.

[40] B. Y. Lu et al., "Bulbs control in virtual reality by using leap motion somatosensory controlled switches," Int. Conf. Adv. Commun. Technol. ICACT, pp. 879-882, 2017.

[41] L. Vokorokos, J. Mihal'Ov, and E. Chovancova, "Motion sensors: Gesticulation efficiency across multiple platforms," INES 2016 - 20th Jubil. IEEE Int. Conf. Intell. Eng. Syst. Proc., pp. 293-298, 2016.

[42] A. T. Cabreira and F. Hwang, "An analysis of mid-air gestures used across three platforms," Proc. 2015 Br. HCI Conf. - Br. HCI '15, pp. 257-258, 2015.

[43] G. Marin, F. Dominio, and P. Zanuttigh, "Hand gesture recognition with jointly calibrated Leap Motion and depth sensor," Multimed. Tools Appl., vol. 75, no. 22, pp. 14991-15015, 2016.

[44] G. Marin, F. Dominio, and P. Zanuttigh, "Hand gesture recognition with leap motion and kinect devices," 2014 IEEE Int. Conf. Image Process. ICIP 2014, pp. 1565-1569, 2014.

[45] S. Ransalu and K. Sisil, "A robust vision-based hand gesture recognition system for appliance control in smart homes," 2012 IEEE Int. Conf. Signal Process. Commun. Comput. ICSPCC 2012, pp. 760-763, 2012.

[46] F. D. Davis, R. P. Bagozzi, and P. R. Warshaw, "User Acceptance of Computer Technology: A Comparison of Two Theoretical Models," Manage. Sci., vol. 35, no. 8, pp. 982-1003, 1989. 
[47] M. Nielsen, M. Störring, T. B. Moeslund, and E. Granum, “A Procedure for Developing Intuitive and Ergonomic Gesture Interfaces for HCI,” pp. 409-420, 2004.

[48] D. Rubin, J., \& Chisnell, Handbook of usability testing: How to plan, design, and conduct effective tests (2nd ed.). 2008.

[49] C. Becker et al., "Requirements: The key to sustainability," IEEE Softw., vol. 33, no. 1 , pp. 56-65, 2016.

[50] Hevner, March, Park, and Ram, "Design Science in Information Systems Research," MIS Q., vol. 28, no. 1, p. 75, 2004. 


\section{APPENDIX 1. Sample feature extraction for Gesture "Lights On"}

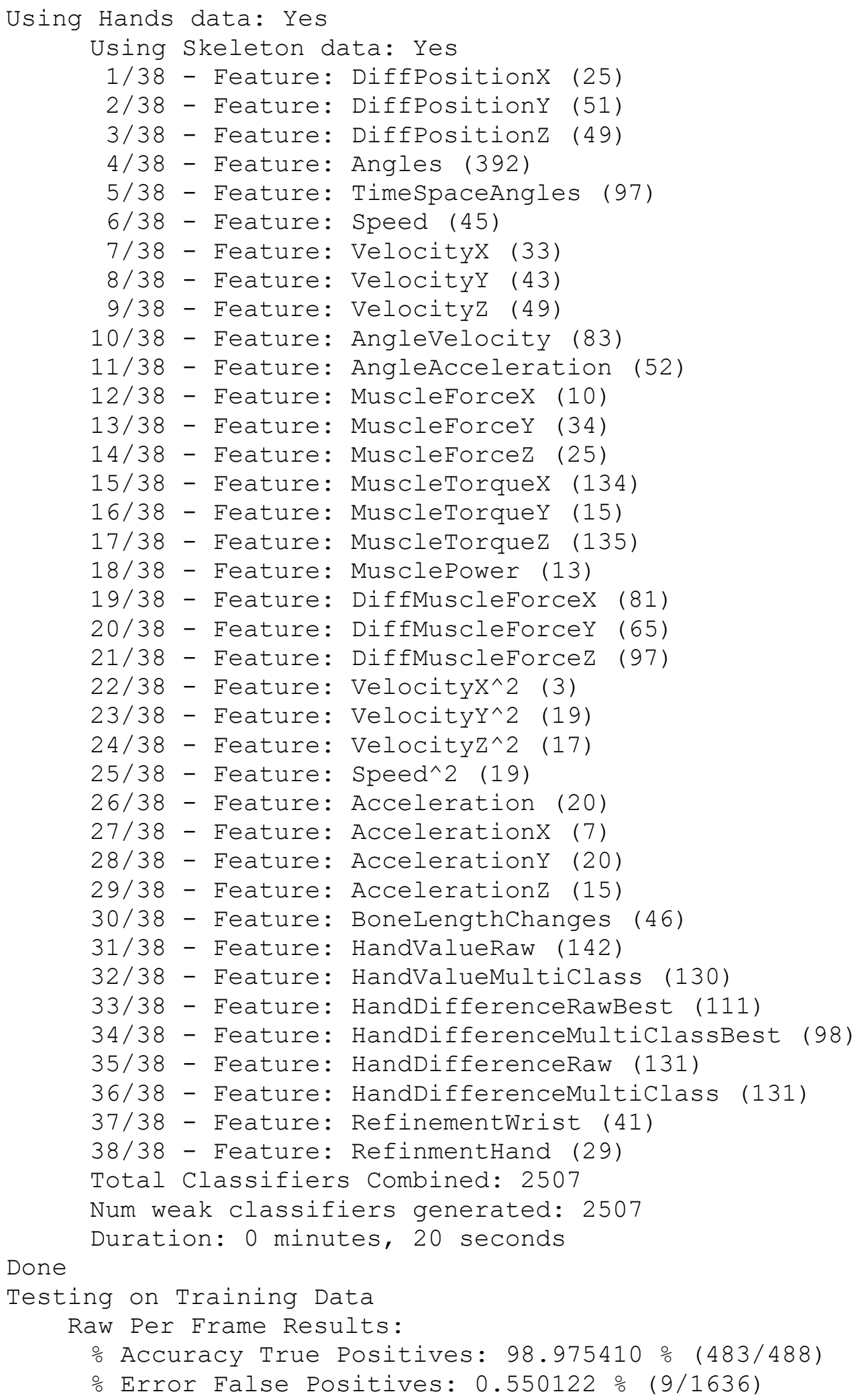




\title{
APPENDIX 2. Informed consent form for minimal risk
}

\author{
$\Delta$ Hochschule Harz \\ Harz University of Applied Sciences
}
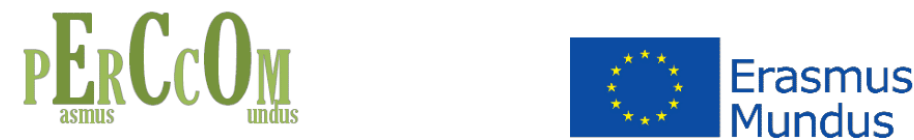

\section{INFORMED CONSENT FORM FOR MINIMAL RISK CLASSROOM ACTIVITIES/ PROJECTS INVOLVING HUMAN PARTICIPANTS}

\section{Information}

\section{Purpose of the Activity}

This activity, entitled Usability Study on Motion Capture Technologies for Smart Homes, is intended to provide preliminary data and observations to understand gesture interactions with home automation systems.

\section{Purpose of the Activity}

I am inviting you,

to participate in this activity. Your participation is purely voluntary, and so you may refuse to participate. Rest assured that non-participation on your part will in no way affect your standing as a student/ member of organization/ community. You may opt to withdraw from participation at any point in the activity even if you have signed this form.

\section{Procedure}

This activity will involve the following procedures:

- Interaction with the motion capture prototype.

- Answer survey/ questionnaire about usability.

- Interview regarding your experience of the technology.

Benefits and Risks

Be aware that the procedure stated above may incur the following risks:

Sharing your time, opinion, and experience; minimal tiredness of the arms and hands. However, these are deemed minimal (i.e., no greater than risks normally incurred on a daily basis or from routine physical examinations), and the benefits to yourself and to the study outweigh the risks. These benefits are: better understanding of gesture interactions with home automation systems.

\section{Confidentiality}

Any data collected in this activity will be shared only with the members of the group and collected materials will not be given identifiers that will match them to you or other participants. Rest assured that your personal information will be protected under the "General Data Protection Regulation" (GDPR EU 2016/679) of the European Union.

\section{Ethical Review}

This activity/project has been reviewed and approved by Hochshule Harz - Department of Automation and Computer Sciences. For concerns, you may contact the thesis supervisor, Prof. Dr. Olaf Drögehorn through odroegehorn@hs-harz.de. 


\section{APPENDIX 2. (continues)}

\section{Certification of Consent}

I have read the foregoing information. I have had the opportunity to ask questions about it and any questions that I have asked been answered to my satisfaction. I consent voluntarily to participate in this project.

\begin{tabular}{|l|l|}
\hline Name of Participant: & \\
\hline Signature of Participant: & \\
\hline Date: & \\
\hline
\end{tabular}

If less than 18 years old,

Having been informed of the purpose of the activity, its procedures, and its associated risks and benefits, I hereby give my consent to my son's/ daughter's participation in the study.

\begin{tabular}{|l|l|}
\hline Name of Guardian: & \\
\hline Signature of Guardian: & \\
\hline Date: & \\
\hline
\end{tabular}

\section{Statement of Principal Investigator/s}

I have provided complete and accurate information regarding the activity/ project to the potential participant and to his/her guardian (if below the age of 18), and to the best of my ability have made sure that the participant understands the following will be done: Usability Study on Motion Capture Technologies for Smart Homes.

I confirm that the participant was given an opportunity to ask questions about the study, and all the questions asked by the participant have been answered correctly and to the best of my ability. I confirm that the individual has not been coerced into giving consent, and the consent has been given freely and voluntarily.

A copy of this informed consent form has been given to the participant.

\begin{tabular}{|l|l|}
\hline Name of Principal Investigator: & MARCEL LOWELL G. VILLANUEVA \\
\hline Signature of Principal Investigator: & \\
\hline Date: & \\
\hline
\end{tabular}

"Using Gestures to Interact with Home Automation Systems"

by: Marcel Lowell G. Villanueva | Erasmus Mundus Master in Pervasive Computing and Communications for Sustainable Development (PERCCOM)

+436603935190 | marvil-7@student.Itu.se 


\title{
APPENDIX 3. Questionnaire for Usability Study on Gesture Control and Interactions for Smart Homes
}

\author{
$\Delta$ Hochschule Harz \\ Harz University of Applied Sciences
}
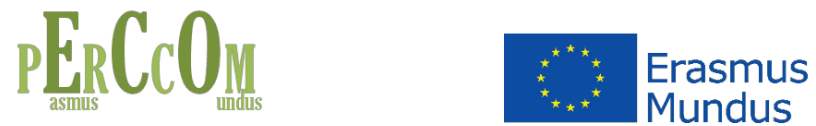

Questionnaire for Usability Study on Gesture Control and Interactions for Smart Homes

Part 1.

1. Age group:
- 17 years old and below
$36-50$
- $18-26$
○ $27-35$
- 51 and above

2. Gender
○ Male
- Other:
- Female
- Preferred not to answer

3. Country of Origin:

4. Current living situation:

- Independently or by myself

- Shared flat or with room mates

- With family

5. Rate your level of technological aptitude. (1=not techy to $5=$ very techy)

\begin{tabular}{lllll}
\hline 1 & 2 & 3 & 4 & 5 \\
\hline
\end{tabular}

Part 2.

6. A smart home is a home that is equipped with technology to remotely control and automate household systems like lighting, thermostats, entertainment systems, and other connected appliances. Do you own any of these devices?
○ Yes
○ No

7. If yes, which devices?
- Smart lighting/ bulb
Smart thermostat
Smart speakers
Smart switches
Smart energy mete
Others:

8. If no, are you interested in smart home devices for your home?

- Yes

No

Part 2. Before the trial

9. Using gesture is a "natural" way of interacting with smart home technologies.

10. Gesture control will improve your overall experience with smart homes.

\begin{tabular}{ccccc}
$\begin{array}{c}\text { Strongly } \\
\text { Disagree }\end{array}$ & Disagree & Neutral & Agree & $\begin{array}{c}\text { Strongly } \\
\text { Agree }\end{array}$ \\
\hline 1 & 2 & 3 & 4 & 5 \\
\hline & & & & \\
\hline 1 & 2 & 3 & 4 & 5 \\
\hline
\end{tabular}

(continues) 


\section{APPENDIX 3. (continues)}

11. Gesture control will make interacting with smart home easier.

12. You will easily get used to smart home interactions with the help of gestures.

13. I think gesture technology will be mature enough to be a typical way of interacting with technologies in the near future.

\section{Part 4. Trial with Prototype/ Gesture Set}

14. The gestures are generally easy to remember.

15. Most gestures are straining to the arms or hands.

16. Most gestures feel very natural to the commands they correspond to, thus easy to learn.

17. The gestures are generally very complex and complicated to perform.

18. It is easy to make errors or mistake with current set of gestures.

19. I am generally satisfied with the gestures used for smart home interactions.

\section{Part 5. Summary/ Debriefing}

20. My culture is known to use (hand/ body) gestures as part of everyday communication and interactions

21. These gestures reflect possible interactions of people from where I am from.

22 My cultural background is known to be very accepting of new/ innovative technologies.

23. In contrast with other media (ie. remote control, voice command, etc), I am open to the idea of communicating with home devices using gestures.

24. I would buy (or invest to) smart home devices to control my home.

25. I would invest to gesture control technologies to interact with my smart home.

\begin{tabular}{ccccc}
$\begin{array}{c}\text { Strongly } \\
\text { Disagree }\end{array}$ & Disagree & Neutral & Agree & $\begin{array}{c}\text { Strongly } \\
\text { Agree }\end{array}$ \\
\hline 1 & 2 & 3 & 4 & 5 \\
\hline & & & & \\
\hline 1 & 2 & 3 & 4 & 5 \\
\hline 1 & & & & \\
\hline & 2 & 3 & 4 & 5 \\
\hline
\end{tabular}

\begin{tabular}{lllll}
\hline 1 & 2 & 3 & 4 & 5 \\
\hline 1 & 2 & 3 & 4 & 5 \\
\hline 1 & 2 & 3 & 4 & 5 \\
\hline
\end{tabular}

\begin{tabular}{lllll}
\hline 1 & 2 & 3 & 4 & 5 \\
\hline & & & & \\
\hline 1 & 2 & 3 & 4 & 5 \\
\hline & & & & \\
\hline 1 & 2 & 3 & 4 & 5 \\
\hline
\end{tabular}

\begin{tabular}{lllll}
\hline 1 & 2 & 3 & 4 & 5 \\
\hline & & & & \\
\hline 1 & 2 & 3 & 4 & 5 \\
\hline
\end{tabular}

\begin{tabular}{lllll}
\hline 1 & 2 & 3 & 4 & 5 \\
\hline
\end{tabular}

\begin{tabular}{lllll}
\hline 1 & 2 & 3 & 4 & 5 \\
\hline
\end{tabular}

\begin{tabular}{lllll}
\hline 1 & 2 & 3 & 4 & 5 \\
\hline
\end{tabular}

$\begin{array}{lllll}1 & 2 & 3 & 4 & 5\end{array}$

Comments: 


\section{APPENDIX 4. Curriculum Vitae of the author}

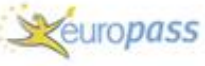

PERSONAL INFORMATION

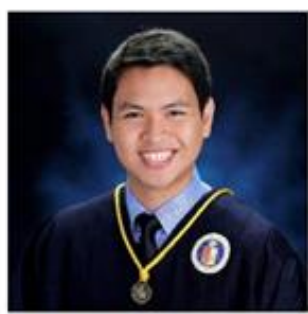

JOB APPLIED FOR

POSITION

PREFERRED JOB STUDIES APPLIED FOR

WORK EXPERIENCE

January 2017 - present

June 2015 - July 2016

April 2014 - March 2015

October 2012 - March 2015
Curriculum Vitae

Marcel Lowell G. Villanueva

\section{Marcel Lowell G. Villanueva}

P Room 43 Villagatan 12A, Skelleftea, Sweden

1. $(+43) 6603935190$

(+63) 9275598720

× marvil.7@student.ltu.se or marcel.villanueva@obf.ateneo.edu

(O) linkedin.com/in/marcelg 39

Skype: marcelgv39@ive.com

Sex Male | Date of birth 06/09/1993 | Nationality Flipino

Doctoral Candidate in Digitalization and Applications of Smart Objects for the Built Environment (Architecture, Engineering, Construction and Facilities Management AECFM)

Erasmus Mundus Students and Alumni Association (EMA)

Programme Representative for PERCCOM

EMA offers an intemational professional and personal network for Erasmus Mundus students and graduates. Our members can join our professional networks and service teams to network and become active within the Association. As the Programme Representative, I manage the everyday activities of the current students - streamlining communications with professors, organizing administrative requirements for mobility, etc.

Business or sector Education, Leadership

John Gokongwei School of Management, Ateneo de Manila University

Lecturer

I served as a part-time faculty of JGSOM - Quantitative Methods and Information Technology department handling 2 classes. Basic Information Technology Applications for Business (ITM11.1) addresses the computer proficiency requirement for all JGSOM majors as well as other businessrelated majors. It is also the starting point for those who want to pursue a minor in Information Technology Management.

Business or sector Education, Information Technology

Council of Organization of the Ateneo (COA)

Science and Technology Cluster Head

As COA: Science and Technology Cluster Head, I help, assist and facilitate collaboration among the 8 accredited student organizations under the Science and Technology Cluster towards the impact they aim for the Ateneo community and the society. In turn, I also represent these organizations to the council, reporting their updates, plans and concerns regularly. In COA, we believe in building a community of student-leaders, and nurturing their core competencies - the things they do best toward building the nation together.

Business or sector Youth engagement, Student-leadership

Microsoft Philippines

Microsoft Student UCrew Core Ambassador/ Microsoft Student Partner

Being hailed as the Microsoft Student UCrew Core Ambassador for Ateneo opened opportunities fo me to tour different schools and universities from around the country to introduce and make a buzz of the company's latest technologies. On a more technical scope, the Microsoft Student Partner programme trains IT students with Microsoft Visual Studio to help develop applications for the new operating systems - Windows 8.1

Business or sector Technology, Consumer electronics, Applications development 


\section{APPENDIX 4. (continues)}

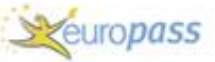

EDUCATIONAND TRAINING

August 2016 - present

June 2010 - March 2015

\section{PERSONAL SKILLS \\ Mother tongue(s)}

Other language(s)

English

Geman
Erasmus Mundus Master in Pervasive Computing and Communications for Sustainable Development - PERCCOM (Multiple Degrees)

Universite de Lorraine (France)

Master in Complex System Engineering

Lappeenranta University of Technology (Finland)

Master of Science (Tech.) in Computer Science

Lulea University of Technology (Sweden)

Master in Pervasive Computing and Communications for Sustainable Development

August 2015 - May 2017 Master of Science in Electronics Engineering

Ateneo de Manila University (Philippines)

- The MS in Electronics Engineering focuses on innovative research in the fields of modern communications, biomedical engineering, energy harvesting, and instrumentation. To make the Philippines successful in global competition in high technology requires innovation and entrepreneurship in the emerging technical fields that have commercial potential. Innovating new products, services and systems is increasingly a multi-disciplined endeavour. A strong science based preparation with engineering subjects is ideal for this course of study. The University provides an excelent opportunity for inter-disciplinary research, with various segments of the School of Science and Engineering contributing new problems and solutions where the graduates can apply their core skills. Students are encouraged to blend core classes, elective classes throughout the University and directed research into a coherent program. The thesis required of all students must demonstrate innovative contributions to the technical community and mastery of a portfolio of projects.

- For my graduate thesis, I am interested in emerging exploring areas in Intemet of Things (IOT) technologies, energy efficiency, Green IT and power informatics. I am currently taking this program under a scholarship from the Republic of the Philippine's Department of Science and Technology Engineering Research and Development for Technology.

Bachelor of Science in Computer Engineering

(with Honours and Program Awards)

Ateneo de Manila University (Philippines)

- This 5-year engineering program prepares students to become quality engineers in information technology and computer applications. Graduates will have good communication and analytical skills gained from mathematics, science, engineering, and elective courses offered by the department. The department puts special emphasis in the field of microelectronics and its application in the rapidly evolving fieid of digital systems. The hands-on and integrative approach aims to train students to become leaders in enterprises dealing with digital technologies.

- For my undergraduate research, my topic is in the field of power management and hardware \& software development.

- I graduated top of my class, receiving the program awards and with honours.

Filipino (Tagalog)

SPEAKNG

WRIING

Listening

Reading

Spcken interaction Spoken production

$\mathrm{C} 2$

$\mathrm{C} 2$

$\mathrm{C} 2$

C2

'TOEFL. Intemet based Test Score: 104 (copy $\alpha$ results available by request)

A2

A2

A2

A2

A2

Levels: A1/2: Basic user - B1/2: independent user - C1/2 Proficient user

Common European Framework of Reference for Languages 


\section{APPENDIX 4. (continues)}

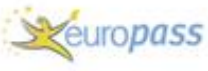

Communication skills

Organisational/ managerial skills

Job-related skills

Computer skills

Other skills

ADDITIONAL INFORMATION

Scholarships, Awards and Recognition

Seminars \& Workshops
I can confidently communicate in English, Filipino, intermediate German, basic French and basic Swedish. My interest in the language-leaming made me sensitive and conscious, giving respect to cultures different from mine.

Leadership plays a big role in characteristics. I also believe that excellence is a habit we pursue every day. In my stay in the university. I continue to hone my leadership potentials in handing and organizing people towards the positive social impact we aim for the community through student-led projects and initiatives.

As a summer intern in Sparksoft Solutions Inc., I was able to apply Software Engineering - design and development, Project Management. Hardware and Software Interfacing. These are lessons from the class room applied in real-world IT solutions.

Software Development: $\mathrm{C}++$ and $\mathrm{CH}$ programming (Microsoft Visual Studios), HTML, PHP and MySQL for web, LINUX, Swift for IOS, Python, Amazon Web Services (AWS)

Harcware Development: AutoCAD, LTSpice and MultiSIM, Arduino IDE, Processing, Basic Compute Networking, Synopsis for VLSI, FPGA programming, Wireshark, NS3 Network Simulator

Project Management: ZOHO Projects, OpenProjects, Trello, online productivity tools by Google and Microsoft OneDrive, Microsoft Office (word processing, slide presentation, spreadsheet formulation) and Adobe Creative Suite (photo editing and manipulation, basic video and sound engineering)

1 believe that the goal really of our Ateneo education is to form its graduates into nation builders leaders in our careers. This is rooted in the university's thrust and core values of shaping future professional for others. Presenting myself, I can confidently communicate in English, Filipino and basic to intermediate German. My interest in the languages made me conscious about sensitivity to people to intermediate German. My interest in the languages made me conscious about sensitivity to people hardware development tools with my core Ateneo courses in Philosophy. Theology and the Humanities trained me to think critically and creatively in different problem solving approaches. I am also very tech-savvy and proficient in MS Office and Adobe Creative Suite softwares. I was able to share these knowledge during my summer stint as a part-tine faculty in Ateneo. Among others, my interest is on finding the link among technology, innovation and their real-world applications to help interest is on finding the link among technology, innovation and their real-world applications to help
address relevant social issues of the Philippines as a developing nation today. Sometimes, I spend my spare time travelling the world - appreciating people and places, with my friends and family. I also involve myself in social relevant causes such as promoting computer literacy among public elementary pupils and nation building through youth engagement.

Erasmus Mundus Master in Pervasive Computing and Communications for Sustainable Development, August 2016

MS Scholarship, Department of Science and Technology - Engineering Research and Development in Technology, August 2015

Nominee, Magsaysay Awards for Future Scientists and Technologists, August 2015 Honorable Mention, Ateneo de Manila University, March 2015

Program Awards, Ateneo de Manila University, March 2015

Leadership Service Recognition for COA, Ateneo de Manila University, March 2015

People Developer Award, Accenture Philippines, 10" Student Leadership Conference, January 2015

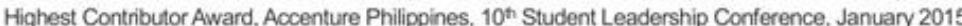

Project Grant, Ateneo Sanggunian (Student Government) Subsidy System, October 2014

SLUSH 2017, Helsinki Finland (November 2017),

European Forum Alpbach (EFA), Alpbach Austria (August 2017)

Erasmus Mundus Student and Alumni Association General Assembly, Brussels Belgium (May 2017).

FTR Forum 2017 - Economy and Technology, Lappeenranta Finland (May 2017).

DIGI Kaappaus - HUB Logistics Hack Challenge, Saimaa Finland (February 2017),

Intemational Conference for Cloudification on Internet of Things in Paris, France (November 2016). 


\section{APPENDIX 4. (continues)}

żeuropass

Sustainable Build Design Manla/ Co-tocated ERDT Conference 2016 (July 2016),

IDEA Global Entrepreneurship Symposium and Workshops (February 2016),

41*Asia Pacific Advanced Network Meeting (APAN) Manila (January 2016),

Institute of Electrical and Electronics Engineering (IEEE) TENCON 2015 in Macau (November 2015),

Summer Study Tour in Germany with Carl Duisberg Centre Berlin (May 2015),

Joint Information Science Workshop with Ateneo de Manila University and Nagoya University

(February 2015),

Accenture Philippines $10^{\text {nn }}$ Student Leadership Conference (January 2015),

Nikkei Recruitment Forum in Japan (August 2014),

Association of Christian Universities and Colleges in Asia Student Camp in Taiwan (August 2014),

ASEAN Career Fair with Japan in Expo Singapore (May 2014).

YouthLeadPH 2014: Youth Leadership Camp (May 2014).

Retrospect: The De La Salle University Engineering Summit 2014 (February 2014),

Charis Leadership Summit 2014 (February 2014),

AECES Interface 2013: Engineering the Future! (November 2013),

9th Philippine Youth Congress for Information Technology: Y4IT (August 2011)

Institute of Electrical and Electronics Engineering (IEEE)

Graduate-student Member (valid until 2016)

IEEE, an association dedicated to advancing innovation and technological excellence for the benefit of humanity, is the world's largest technical professional society. It is designed to serve professionals involved in all aspects of the electrical, electronic, and computing fields and related areas of science and technology that underlie modem civilization.

Asia Pacific Advanced Network (APAN)

Asia Pacific Advanced Network (APAN) 41 Fellow

APAN (the Asia Pacific Advanced Network) refers to both the organisation representing its members, and to the backbone network that connects the research and education networks of its member countries/economies to each other and to other research networks around the world. APAN members are the entities representing research and education network interests in the countries/economies of Asia and Oceania. APAN coordinates activities related to network technologies, services, and applications among its members and with its peer international organisations.

APAN is also a key driver in promoting and facilitating network-enabled research and education activities. These include research collaboration, knowledge discovery and shaning, tele-health and natural disaster mittigation. The 41 st Meeting of APAN will be held at the Marriott Hotel Manila, Pasay City, Metro Manila, Philippines form 24th - 29th January 2016

"Appliance recognition system for ILM using AGILASx - Dataset of common appliances in the Philippines" Villanueva, et.al, Ateneo de Manila University, 2016

Cloudification of Internet of Things (CloT 2016), Paris, France.

'Wireless Power Consumption Monitoring and Analysis System Using Winter's Forecasting Method' Enriquez and Villanueva, Ateneo de Manila University, Philippines, 2015. Institute of Electrical and Electronics Engineering (IEEE) Region 10 Conference: TENCON 2015

"both are available in IEEEXplore or by request from the author 